\title{
RESEARCH
}

Open Access

\section{CRID3, a blocker of apoptosis associated speck like protein containing a card, ameliorates murine spinal cord injury by improving local immune microenvironment}

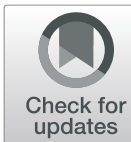

Yu-Qing Chen ${ }^{1,2,3,4 \dagger}$, Sai-Nan Wang ${ }^{1,2,3,4 \dagger}$, Yu-Jiao Shi ${ }^{1,2 \dagger}$, Jing Chen ${ }^{1,2,3,4}$, Shu-Qin Ding ${ }^{1}$, Jie Tang ${ }^{3,4}$, Lin Shen ${ }^{2}$, Rui Wang ${ }^{2}$, Hai Ding ${ }^{2}$, Jian-Guo Hu ${ }^{1,2^{*}}$ and He-Zuo Lü $\ddot{u}^{1,2,3,4^{*}}$ (D)

\begin{abstract}
Background: After spinal cord injury (SCl), destructive immune cell subsets are dominant in the local microenvironment, which are the important mechanism of injury. Studies have shown that inflammasomes play an important role in the inflammation following $\mathrm{SCl}$, and apoptosis-associated speck-like protein containing a card (ASC) is the adaptor protein shared by inflammasomes. Therefore, we speculated that inhibiting ASC may improve the local microenvironment of injured spinal cord. Here, CRID3, a blocker of ASC oligomerization, was used to study its effect on the local microenvironment and the possible role in neuroprotection following SCl.

Methods: Murine SCI model was created using an Infinite Horizon impactor at T9 vertebral level with a force of 50 kdynes and CRID3 $(50 \mathrm{mg} / \mathrm{kg}$ ) was intraperitoneally injected following injury. ASC and its downstream molecules in inflammasome signaling pathway were measured by western blot. The immune cell subsets were detected by immunohistofluorescence (IHF) and flow cytometry (FCM). The spinal cord fibrosis area, neuron survival, myelin preservation, and functional recovery were assessed.

Results: Following SCI, CRID3 administration inhibited inflammasome-related ASC and caspase-1, IL-1 3 , and IL-18 activation, which consequently suppressed M1 microglia, Th1 and Th1Th17 differentiation, and increased M2 microglia and Th2 differentiation. Accordingly, the improved histology and behavior have also been found.

Conclusions: CRID3 may ameliorate murine SCI by inhibiting inflammasome activation, reducing proinflammatory factor production, restoring immune cell subset balance, and improving local immune microenvironment, and early administration may be a promising therapeutic strategy for SCl.
\end{abstract}

Keywords: Spinal cord injury, CRID3, Inflammasome, Apoptosis-associated speck-like protein containing a card, Immune microenvironment, Locomotor recovery

* Correspondence: jghu9200@163.com; Ihz233003@163.com

tYu-Qing Chen, Sai-Nan Wang and Yu-Jiao Shi contributed equally to this

work

${ }^{1}$ Clinical Laboratory, The First Affiliated Hospital of Bengbu Medical College,

233004 Bengbu, Anhui, People's Republic of China

Full list of author information is available at the end of the article

C The Author(s). 2020 Open Access This article is licensed under a Creative Commons Attribution 4.0 International License, which permits use, sharing, adaptation, distribution and reproduction in any medium or format, as long as you give appropriate credit to the original author(s) and the source, provide a link to the Creative Commons licence, and indicate if changes were made. The images or other third party material in this article are included in the article's Creative Commons licence, unless indicated otherwise in a credit line to the material. If material is not included in the article's Creative Commons licence and your intended use is not permitted by statutory regulation or exceeds the permitted use, you will need to obtain permission directly from the copyright holder. To view a copy of this licence, visit http://creativecommons.org/licenses/by/4.0/. The Creative Commons Public Domain Dedication waiver (http://creativecommons.org/publicdomain/zero/1.0/) applies to the data made available in this article, unless otherwise stated in a credit line to the data. 


\section{Background}

Spinal cord injury (SCI) is the damage of the spinal cord caused by various reasons, resulting in paralysis, loss of sensation, and related organ dysfunction [1]. SCI has a high disability rate and currently lacks effective treatment, so it is a serious disaster to the patients with SCI in physical, psychological, and economic aspects, and it is also one of the most serious public problems in the world $[1,2]$. Therefore, exploring the effective treatment of SCI is of great significance for improving the quality of life of patients and reducing the burden of social medical care.

The pathological process of SCI includes primary injury and secondary injury. Primary injury refers to the direct injury of mechanical force to the spinal cord, which cannot be interfered clinically [3]. Secondary injury refers to local inflammation, edema, ischemia, and electrolyte changes, among which inflammation is one of the main damage factors $[4,5]$. The inflammatory response is characterized by infiltration and activation of inflammatory cells in the injured spinal cords, which leads to the increase of inflammatory cells and inflammatory factors, and formation of inflammatory microenvironment, finally leading to spinal cord dysfunction [6]. Therefore, early and effective anti-inflammatory treatment and improvement of local immune microenvironment are important for protecting residual neurons and promoting functional recovery.

Inflammasome is a high molecular weight multiprotein complex discovered by Martinon et al. in 2002 [7]. It is mainly composed of three parts: intracellular pattern recognition receptor, caspase-1, and adaptor protein (apoptosis-associated speck-like protein containing a card, ASC). When encountering external or internal stimuli, inflammasome can recognize pathogen-associated molecular patterns (PAMPs) or damage-associated molecular patterns (DAMPs) from the host through pattern recognition receptors, and then ASC can recruit and activate procaspase- 1 into caspase- 1 , which can further cleave and activate IL-1 family cytokines (such as IL-1 $\beta$ and IL-18), and finally lead to the downstream inflammatory cascade and pyroptosis [7-11].

In the central nervous system (CNS), inflammasomes are found in neurons, astrocytes, and microglia [12-15]. The intracellular pattern recognition receptors are NLRP1 and AIM2 in neurons, NLRP2 in astrocytes, and NLRP3 in microglia $[12,13]$. NLRP1 inflammasome is composed of NLRP1, caspase-1, caspase-11, ASC, and $\mathrm{X}$-linked inhibitor of apoptosis protein (XIAP), which was found by de Rivero Vaccari in the injured spinal cord in 2008 [14]. NLRP2 inflammasome has been found in the cultured astrocytes. It is composed of NLRP2, caspase-1, and ASC. It interacts with P2X7 receptor and pannexin-1, a channel protein, and can be activated by a high concentration of ATP [15]. NLRP3 complex is the best-characterized inflammasome, which contains NLRP3, caspase-1, and ASC. Recent researches also confirmed that it has obvious expression and activation following SCI $[16,17]$. These demonstrated that inflammasomes may play an important role in the inflammation of SCI. Because ASC is the adaptor protein shared by inflammasomes, we speculated that ASC can be used as a target to inhibit the activation of inflammasomes, so as to improve the local immune microenvironment of SCI and reduce nerve damage. In this study, CRID3, a blocker of ASC oligomerization [18], was used to study its effect on the local microenvironment and the possible role in neuroprotection following SCI.

\section{Methods \\ Animals}

A total of 130 female C57BL/6 mice (weight, $18-20 \mathrm{~g}$; age, 8 weeks old) obtained from Chang Zhou Cavens Laboratory Animal Ltd. Animals were housed in ventilated cages and maintained on a 12-h light/dark cycle with ad libitum access to food and water. Ambient room temperature was maintained at $20 \sim 22^{\circ} \mathrm{C}$ with $30 \sim$ $70 \%$ humidity. Animal care following surgery complied with the regulations for the management of experimental animals (revised by the Ministry of Science and Technology of China in June 2004). The study was approved by the Institutional Committee on Animal Care, Use, and Research of the Bengbu Medical College. During the experiment, 10 mice died and 120 survived. Table 1 provided a comprehensive description of the total number of mice used per group in each experiment.

\section{Contusive $\mathrm{SCl}$ and drug injection}

An Infinite Horizon impactor (Precision Systems and Instrumentation) was used to perform contusive SCI, as previously described $[19,20]$. The mice were first anesthetized with a cocktail of ketamine $(80 \mathrm{mg} / \mathrm{kg}) /$ xylazine $(10 \mathrm{mg} / \mathrm{kg})$ intraperitoneally injection, and then the T9 lamina was excised. The spine was stabilized by clamping the T7 and T11 spinous processes, and then a moderate SCI model was created using a $\operatorname{rod}(1.3 \mathrm{~mm}$ in diameter) with a force of 50 kdynes. Sham-operated (sham) mice only received a laminectomy without contusive injury. Post-surgically, mice were placed in a temperature- and humidity-controlled chamber. Manual bladder emptying was performed three times daily until reflex bladder emptying was established. To relieve the postoperative pain, meloxicam $(5 \mathrm{mg} / \mathrm{kg}$, CSNpharm, IL, USA) were injected subcutaneously at $12 \mathrm{~h}$ time intervals following surgery for 7 days. To prevent infections, animals were daily provided with chloramphenicol $(50 \mathrm{mg} /$ $\mathrm{kg}$ ) via drinking water. The spinal cord-injured mice were randomly assigned to the vehicle control or CRID3 
Table 1 The total number of mice used per group in each experiment

\begin{tabular}{|c|c|c|c|}
\hline \multicolumn{3}{|c|}{ Description } & \multirow{2}{*}{$\begin{array}{l}\text { Animal } \\
\text { numbe }\end{array}$} \\
\hline Mice & Experiment & & \\
\hline \multirow[t]{6}{*}{ Survived } & Western blot (WB) & & 18 \\
\hline & Immunohistofluorescen & & 18 \\
\hline & Flow cytometry (FCM) & Microglia and macrophages, M1, and M2 & 18 \\
\hline & & Th1, Th2, and Th17 & 18 \\
\hline & & Treg and Tc & 18 \\
\hline & Histology and behavior & & 30 \\
\hline Died & \multicolumn{2}{|c|}{ N/A } & 10 \\
\hline Total & \multicolumn{2}{|c|}{ N/A } & 130 \\
\hline
\end{tabular}

injection groups. The CRID3 concentration chosen for this study was based on published reports [21-23]. Mice were intraperitoneally injected with $0.01 \mathrm{M} \mathrm{PBS}$ (pH 7.4) or CRID3 (Target Molecule Corp., $50 \mathrm{mg} / \mathrm{kg}$ prepared in PBS) immediately following injury one dose per day and continuing for 7 days.

\section{Western blot analysis}

Three days following surgery, the mice were euthanized with a cocktail of ketamine $(80 \mathrm{mg} / \mathrm{kg}) /$ xylazine $(10 \mathrm{mg} /$ $\mathrm{kg}$ ) intraperitoneally injection and perfused with $10 \mathrm{ml}$ cold 0.01 M PBS ( $\mathrm{pH} 7.4$ ). After perfusion, the 5-mm spinal cord segments containing the injury epicenter (or the same spinal cord segments in the sham group) were removed ( $n=6$ in every group). Total protein was extracted from the spinal cords and western blot analysis was performed as previously described [24]. The primary and secondary antibodies used were listed in Table 2. Finally, an ECL kit (Cat. \# 35055, Pierce) was used to observe the immunoreactive protein. Gel-Pro analyzer (Media Cyrnistic, Silver Spring, MD) was used to digitize the membrane and determine the band's density.

\section{Immunohistofluorescence}

Seven days following surgery, the mice were euthanized as described above, then transcardially exsanguinated with $10 \mathrm{ml} \mathrm{0.01} \mathrm{M} \mathrm{PBS} \mathrm{(pH} \mathrm{7.4)} \mathrm{followed} \mathrm{by} \mathrm{fixation} \mathrm{with}$ $20 \mathrm{ml}$ ice-cold 4\% PFA in $0.01 \mathrm{M} \mathrm{PBS} \mathrm{(pH} \mathrm{7.4).} \mathrm{After}$ perfusion, the $5 \mathrm{~mm}$ spinal cord segments containing the injury epicenter (or the same spinal cord segments in sham group) were removed ( $n=6$ in every group), postfixed overnight in $4 \%$ paraformaldehyde (PFA) in $0.01 \mathrm{M}$ PBS (pH 7.4), and transferred to $30 \%$ sucrose in $0.01 \mathrm{M}$ PBS (pH 7.4) at $4{ }^{\circ} \mathrm{C}$ overnight. Then, the segments were placed in OCT compound embedding medium (TissueTek, Miles, Elkart, IN) and $5 \mu \mathrm{m}$ frozen sections were obtained longitudinally using a cryostat (Leica CM1900, Bannockburn, IL), followed by thaw-mounting on polyL-lysine-coated slides. For immunohistochemical assay, the primary antibodies (Table 2) were incubated overnight at $4{ }^{\circ} \mathrm{C}$. The following day, after being rinsed with $0.01 \mathrm{M} \mathrm{PBS}$, the sections were incubated with FITC- or rhodamine-conjugated secondary antibodies (Table 2) at $37^{\circ} \mathrm{C}$ for $1 \mathrm{~h}$. Finally, the slides were washed, coverslipped with installation medium containing nuclear dye Hoechst 33342 (0.5 $\mu \mathrm{m}$, sigma), and examined using a ZWISS Axio observation microscope. The spinal cord cross sections from six mice in every group were used for cell quantification. Five complete sections per animal were analyzed in a blinded fashion, and cell numbers were calculated as cells in a set of five slides from rostral to caudal containing the injury epicenter as previously described [25].

\section{Flow cytometry}

Seven days following surgery, the mice were euthanized as described above, then the $5 \mathrm{~mm}$ spinal cord segments containing the injury epicenter (or the same spinal cord segments in the sham group) were removed $(n=6$ in every group), and the spinal cords were removed by insufflation and dissociated by gently grinding the tissue into a single-cell suspension through a $45-\mu \mathrm{m}$ nylon mesh with the plunger of a syringe. The cells were isolated by Percoll (Amersham Pharmacia Biotech, Piscataway, NJ, USA) gradient centrifugation as previously described [26]. Different panel of fluorescent-labeled antibodies (Table 2) were used to identify different immune cell subtypes. After incubation at $4{ }^{\circ} \mathrm{C}$ for $30 \mathrm{~min}$, cells were washed three times with $0.01 \mathrm{M} \mathrm{PBS}(\mathrm{pH} 7.4$ ), fixed with $1 \%$ PFA and analyzed using a BD Accuri flow cytometer (Becton Dickinson, San Diego, CA). Isotypematched antibodies (Table 2) were used to control for non-specific staining that was subtracted from specific staining results. A minimum of 100,000 events were collected and analyzed by the FlowJo 7.6.1 software (TreeStar Inc., Ashland OR).

\section{Histological analyses}

Six weeks following surgery, the spinal cords in all groups were collected ( $n=10$ in every group), fixed, 
Table 2 Table of antibodies used

\begin{tabular}{|c|c|c|c|c|c|c|c|}
\hline Antigen & $\begin{array}{l}\text { Host species } \\
\text { and clone }\end{array}$ & Cat. \# or Lot \# & RRID & Conjugation & Source & $\begin{array}{l}\text { Used } \\
\text { concentration }\end{array}$ & Methods \\
\hline ASC & Rabbit polyclonal & $a b \times 013852$ & & & Abbexa & $1: 1000$ & WB \\
\hline caspase-1 & Rabbit monoclonal & ab179515 & & & Abcam & $1: 1000$ & \\
\hline$\beta$-actin & Rabbit polyclonal & BL005B & & & Biosharp & $1: 2000$ & \\
\hline IL-18 & Rabbit polyclonal & PA5-79481 & AB_2746597 & & Invitrogen & $1: 1000$ & \\
\hline$I L-1 \beta$ & Rabbit polyclonal & ab9722 & & & Abcam & $1: 1000$ & \\
\hline $\begin{array}{l}\text { Rabbit lgG } \\
(H+L)\end{array}$ & Goat polyclonal & BL003A & & HRP & Biosharp & $1: 10,000$ & \\
\hline CD11b & Rat monoclonal & $14-0112-82$ & AB_467108 & & Invitrogen & $1: 200$ & $\mathrm{HF}$ \\
\hline CD45 & Rat monoclonal & $14-0451-82$ & AB_467251 & & & & \\
\hline CD68 & Rat monoclonal & MA5-16674 & AB_2538168 & & & & \\
\hline CCR7 & Rabbit polyclonal & ab191575 & & & Abcam & & \\
\hline Arg1 & Rabbit polyclonal & PA5-29645 & AB_2547120 & & Invitrogen & & \\
\hline CD4 & Rat monoclonal & $14-9766-82$ & AB_2573008 & & & & \\
\hline CD4 & Rabbit polyclonal & PA5-87425 & AB_2804136 & & & & \\
\hline GATA3 & Rabbit polyclonal & PA5-20892 & AB_11154392 & & & & \\
\hline T-bet & Rabbit polyclonal & PA5-40573 & AB_2576589 & & & & \\
\hline ROR gamma (t) & Rabbit polyclonal & PA5-23148 & AB_2540675 & & & & \\
\hline FOXP3 & Rat monoclonal & $14-4776-82$ & AB_467554 & & & & \\
\hline Rat $\lg G(H+L)$ & Goat polyclonal & $112-095-143$ & AB_2338199 & Fluorescein (FITC) & Jackson & & \\
\hline $\begin{array}{l}\text { Rabbit lgG } \\
(H+L)\end{array}$ & Goat polyclonal & $111-025-144$ & AB_2337932 & Rhodamine (TRITC) & DResearch & & \\
\hline CCR7 & Rat monoclonal & $47-1971-82$ & AB_2573974 & APC-eFluor 780 (AF780) & Invitrogen & $0.25 \mu \mathrm{g} / \mathrm{test}$ & FCM \\
\hline $\begin{array}{l}\text { lgG2b kappa } \\
\text { isotype control }\end{array}$ & Rat & $47-4321-82$ & AB_1271997 & APC-eFluor 780 (AF780) & & $0.25 \mu \mathrm{g} / \mathrm{test}$ & \\
\hline CD11b & Rat monoclonal & $12-0112-81$ & AB_465546 & PE & & $0.125 \mu \mathrm{g} /$ test & \\
\hline CD3 & Rat monoclonal & $12-0032-82$ & AB_2811741 & PE & & $0.25 \mu \mathrm{g} /$ test & \\
\hline $\begin{array}{l}\text { IgG2b kappa } \\
\text { isotype control }\end{array}$ & Rat & $12-4031-82$ & AB_470042 & PE & & $0.25 \mu \mathrm{g} /$ test & \\
\hline CD127 & Rat monoclonal & $48-1273-82$ & AB_2574039 & eFlour 450 & & $0.5 \mu \mathrm{g} / \mathrm{test}$ & \\
\hline $\begin{array}{l}\text { IgG2b kappa } \\
\text { isotype control }\end{array}$ & Rat & $48-4031-82$ & AB_1272017 & eFlour 450 & & $0.5 \mu \mathrm{g} /$ test & \\
\hline CD183 & $\begin{array}{l}\text { Armenian hamster } \\
\text { monoclonal }\end{array}$ & $62-1831-82$ & AB_2762747 & Super Bright 436 (SB436) & & $0.5 \mu \mathrm{g} /$ test & \\
\hline $\begin{array}{l}\text { lgG isotype } \\
\text { control }\end{array}$ & Armenian Hamster & $62-4888-82$ & AB_2717007 & Super Bright 436 (SB436) & & $0.5 \mu \mathrm{g} / \mathrm{test}$ & \\
\hline CD196 & Rat monoclonal & $50-7196-82$ & AB_11219682 & eFlour 660 & & $0.5 \mu \mathrm{g} /$ test & \\
\hline $\begin{array}{l}\text { IgG2a kappa } \\
\text { isotype control }\end{array}$ & Rat & $50-4321-82$ & AB_10598503 & eFlour 660 & & $0.5 \mu \mathrm{g} /$ test & \\
\hline CD25 & Rat monoclonal & $47-0251-82$ & AB_1272179 & APC-eFluor 780 (AF780) & & $0.5 \mu \mathrm{g} /$ test & \\
\hline $\begin{array}{l}\text { IgG1 kappa } \\
\text { isotype control }\end{array}$ & Rat & $47-4301-80$ & AB_1271986 & APC-eFluor 780 (AF780) & & $0.5 \mu \mathrm{g} /$ test & \\
\hline CD28 & $\begin{array}{l}\text { Syrian hamster } \\
\text { monoclonal }\end{array}$ & $45-0281-80$ & AB_925744 & PerCP-Cyanine5.5 (PE-cy5.5) & & $0.5 \mu \mathrm{g} / \mathrm{test}$ & \\
\hline $\begin{array}{l}\text { lgG isotype } \\
\text { control }\end{array}$ & Armenian hamster & $45-4888-80$ & AB_906260 & PerCP-Cyanine5.5 (PE-cy5.5) & & $0.5 \mu \mathrm{g} / \mathrm{test}$ & \\
\hline CD3 & $\begin{array}{l}\text { Armenian hamster } \\
\text { monoclonal }\end{array}$ & $47-0031-82$ & AB_11149861 & APC-eFluor 780 (AF780) & & $0.5 \mu \mathrm{g} / \mathrm{test}$ & \\
\hline $\operatorname{lgG}$ isotype & Armenian hamster & $47-4888-80$ & AB_1271978 & APC-eFluor 780 (AF780) & & $0.5 \mu \mathrm{g} /$ test & \\
\hline
\end{tabular}


Table 2 Table of antibodies used (Continued)

\begin{tabular}{|c|c|c|c|c|c|c|}
\hline Antigen & $\begin{array}{l}\text { Host species } \\
\text { and clone }\end{array}$ & Cat. \# or Lot \# & RRID & Conjugation & Source & $\begin{array}{l}\text { Used } \\
\text { concentration }\end{array}$ \\
\hline \multicolumn{7}{|l|}{ control } \\
\hline CD4 & Rat monoclonal & $11-0041-82$ & AB_464892 & FITC & & $0.25 \mu \mathrm{g} /$ test \\
\hline CD68 & Rat monoclonal & MA5-16676 & AB_2538170 & FITC & & $0.25 \mu \mathrm{g} /$ test \\
\hline $\begin{array}{l}\text { lgG2b kappa } \\
\text { isotype control }\end{array}$ & Rat & $11-4031-82$ & AB_470004 & FITC & & $0.25 \mu \mathrm{g} /$ test \\
\hline CD45 & Rat monoclonal & $17-0451-82$ & AB_469392 & APC & & $0.125 \mu \mathrm{g} / \mathrm{test}$ \\
\hline $\begin{array}{l}\text { IgG2b kappa } \\
\text { isotype control }\end{array}$ & Rat & $17-4031-82$ & AB_470176 & APC & & $0.125 \mu \mathrm{g} / \mathrm{test}$ \\
\hline
\end{tabular}

wrapped, and cut into 5- $\mu \mathrm{m}$ sections were obtained longitudinally using a cryostat (Leica CM1900, Bannockburn, IL), followed by thaw-mounting on poly-L-lysinecoated slides as described in "Immunohistochemical assay." Then, three sets of slides (each set containing serial sections spaced $0.25 \mathrm{~mm}$ apart) were stained with hematoxylin-eosin (HE, Beyotime Biotechnology, Shanghai, China), Luxol fast blue (LFB, Sigma-Aldrich, St. Louis, MO, USA), and Nissl staining (Beyotime Biotechnology) according to the manufacturer's instructions, respectively, to identify fibrosis area, myelinated white matter, and residual ventral horn motoneurons. Lesion epicenter was defined as the section containing the least amount of spared white matter. The images of transverse sections were collected at the lesion epicenter and $0.25,0.5,1$, and $1.5 \mathrm{~mm}$ rostral and caudal to the epicenter using a ZWISS Axio observation microscope. The myelinated white matter was quantified by Image proplus 5.1 (Media Cybernetics, Inc., Atlanta, GA, USA) and the number of surviving ventral horn neurons was confirmed by the exhibition of Nissl substance, euchromatic nucleus, and nucleolus [27]. The fibrosis area and cell quantification were performed using the ImageJ software (http://rsb.info.nih.gov/ij/; National Institutes of Health, Maryland, USA) in an unbiased stereological manner as previously described [28].

\section{Basso mouse scale for locomotion}

Behavioral assessment was performed using BMS, a 10point scale (0-9) based on observations of hind-limb movements of mouse freely moving in an open field [29]. The BMS scores were evaluated at 1 and 3 days, then 1, 2, 3, 4, 5-, and 6-weeks following injury. During the evaluation, mice were walked freely on the openfield surface for $4 \mathrm{~min}$, while being observed by two blinded scorers.

\section{Statistical analyses}

The histological and behavioral data were analyzed using repeated measures, two-way ANOVA statistical test, followed by post hoc analysis for multiple comparisons.
Other data were analyzed using non-parametric KruskalWallis ANOVA, followed by individual Mann-Whitney $U$ tests. Statistical differences were considered significant at $P<0.05$.

\section{Results \\ CRID3 inhibits ASC-related molecule expression and action following $\mathrm{SCl}$}

To verify the effect of CRID3 on ASC-related molecule expression and activation, the homogenate extracts obtained from sham, vehicle, and CRID3-treated injured spinal cords were detected by WB. As shown in Fig. 1, ASC (26 kDa), cleaved-caspase-1 (12/10 kDa), IL-1ß (17 $\mathrm{kDa})$, pro-IL-18 (24/22 kDa), and IL-18 (18 kDa) significantly increased in SCI (vehicle) compared with sham group (all $P<0.01, n=6$ ), while they significantly decreased in SCI (CRID3) compared with SCI (vehicle) group $(P<0.05$ or $0.01, n=6)$. Pro-caspase- $1(45 / 42$ $\mathrm{kDa}$ ) had no differences among the three groups (all $P>$ $0.05, n=6)$. Although the $32 \mathrm{kDa}$ pro-IL- $1 \beta$ had no difference between the sham and SCI (vehicle) group $(P>$ $0.05, n=6$ ), it significantly decreased in SCI (CRID3) compared with SCI (vehicle) group $(P<0.01, n=6)$. These are enough to indicate that CRID3 can inhibit ASC-related molecule expression and activation following SCI.

\section{CRID3 inhibits SCl-induced microglia differentiation into $M 1$ and increases them into $M 2$ cells}

To determine the effect of CRID3 on the number and status of microglia and infiltrated macrophages in the injured spinal cord, we used immunofluorescence double staining to label CD11b with CD68 and CD45, respectively. CD45 is the common marker of peripheral leukocytes [30, 31], CD11b is the common marker of macrophages and microglia [32], CD68 is the common marker of activated macrophages and microglia [33, 34]. $\mathrm{CD}_{4} 5^{+} \mathrm{CD} 11 \mathrm{~b}^{+}$can accurately label macrophages from peripheral blood, and $\mathrm{CD} 8^{+} \mathrm{CD} 11 \mathrm{~b}^{+}$can accurately label activated macrophages and microglia. As shown in Fig. 2, $\mathrm{CD}^{+} 8^{+}$cells (a) and $\mathrm{CD}^{+} 5^{+}$cells (d) in sham 


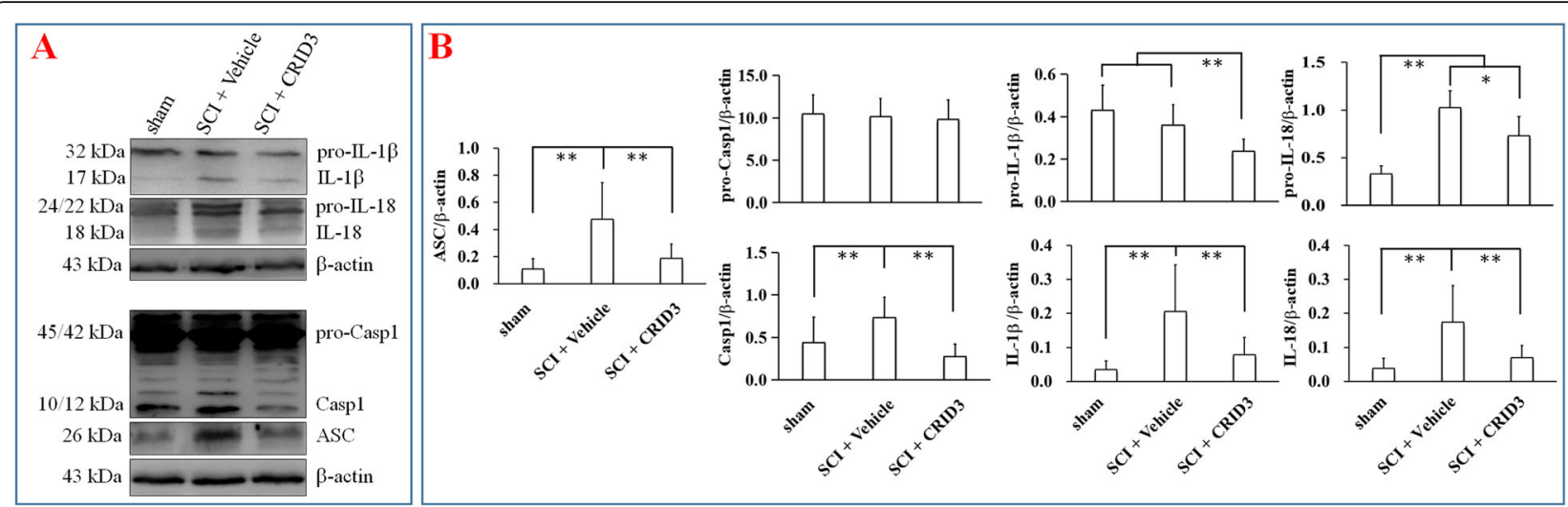

Fig. 1 CRID3 inhibits ASC-related molecule expression and action following SCI. a The representative WB results of the expression of ASC (26

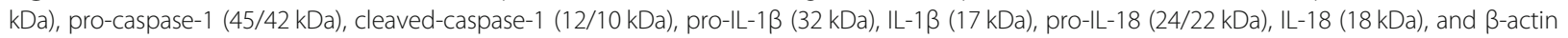
$(43 \mathrm{kDa})$. $\mathbf{b}$ The statistical graphs. Data represent the mean $\pm \mathrm{SD}(n=6) .{ }^{*} P<0.05,{ }^{* *} P<0.01$ (non-parametric Kruskal-Wallis ANOVA, followed by individual Mann-Whitney $U$ tests)

group were very rare, they significantly increased following SCI (b and e) compared with sham group ( $\mathrm{g}$ and $\mathrm{h}$, $P<0.01, n=6$ ). After administration of CRID3 (c and f), CD $45^{+}$cells in SCI (CRID3) group had no significant difference compared with SCI (vehicle) group $(\mathrm{g}, P>$ $0.05, n=6$ ), while $\mathrm{CD} 8^{+}$cells decreased (c), which was significantly different from SCI (vehicle) group (h, $P<$ $0.05, n=6$ ). In sham group (a and d), typical microglia with a number of tiny processes could be detected. After SCI, their morphology became round or oval (b and e), and the number increased significantly (i). There was a significant difference between SCI (vehicle) and sham groups (i, $P<0.05, n=6$ ). After CRID3 administration, $\mathrm{CD}_{11 b^{+}}$cells decreased (c, f, and i), which was significantly different from SCI (vehicle) group (i, $P<0.01, n=$ 6). $\mathrm{CD} 8^{+} \mathrm{CD} 11 \mathrm{~b}^{+}$cells (a) and $\mathrm{CD} 45^{+} \mathrm{CD} 11 \mathrm{~b}^{+}$cells (d) were not detected in the sham group, and both increased significantly following SCI (b, e, j, and k, both $P<0.01$, $n=6)$. After CRID3 administration, $\mathrm{CD} 68^{+} \mathrm{CD} 11 \mathrm{~b}^{+}$cells were significantly decreased $(C)$ compared with SCI (vehicle) group (j, $P<0.01, n=6)$, however, $\mathrm{CD} 45^{+} \mathrm{CD} 11 \mathrm{~b}^{+}$ cells (f) had no significant difference between SCI (vehicle) and SCI (CRID3) groups $(k, P>0.05, n=6)$. These results indicate that following SCI, the infiltration of peripheral leukocytes could be detected in the injured spinal cords, among them macrophages are dominant, and the activation of macrophages and/or local microglia could also be detected; CRID3 has no significant effect on the infiltration of macrophages, but it can inhibit the activation of macrophages and/or local microglia.

To determine the effect of CRID3 on the proportion and status of microglia and infiltrated macrophages in the injured spinal cord, the panel of CD45, CD11b, and CD68 molecules were detected by FCM. Because of there might be low expression of CD45 in the activated microglia $[35,36]$, we defined $\mathrm{CD} 45^{\text {high }}$ cells as peripheral infiltrated leukocytes, $\mathrm{CD}^{+} 8^{+} \mathrm{CD} 11 \mathrm{~b}^{+}$cells as activated macrophages and microglia, $\mathrm{CD} 45^{\text {high }} \mathrm{CD} 11 \mathrm{~b}^{+}$ cells as peripheral derived macrophages, $\mathrm{CD} 45^{-/ \text {low }} \mathrm{CD} 11 \mathrm{~b}^{+}$cells as microglia, $\mathrm{CD} 45^{\text {high }} \mathrm{CD} 68^{+}$ cells as activated peripheral derived macrophages, $\mathrm{CD} 45^{-/ \text {low }} \mathrm{CD}^{+} 8^{+}$cells as activated microglia, and $\mathrm{CD} 45^{\text {high }} \mathrm{CD} 68^{-} \mathrm{CD} 11 \mathrm{~b}^{-}$cells as peripheral-derived leukocytes excluding macrophages. As shown in Fig. 3, in the FSC/SSC pseudocolor plot, we set the same size "region" of the nucleated cells for each sample, and then analyze the proportion of each cell population. The results showed that except $\mathrm{CD} 45^{-/ \mathrm{low}} \mathrm{CD} 11 \mathrm{~b}^{+}$cells, the proportions of the other cell subsets in the SCI (vehicle) group were significantly increased compared with the sham group $(P<0.01$ or $0.05, n=6)$, and CRID3 could significantly decreased the cell subsets of $\mathrm{CD}^{+} 8^{+}$, $\mathrm{CD}_{11 \mathrm{~b}}{ }^{+}, \mathrm{CD} 68^{+} \mathrm{CD} 11 \mathrm{~b}^{+}$, and $\mathrm{CD} 45^{-/ \mathrm{low}^{2}} \mathrm{CD} 68^{+}$(all $\mathrm{P}<$ $0.01, n=6)$ and had no influence on the other cell subsets (all $P>0.05, n=6$ ).

The results of IHF and FCM showed that the microglia in the sham-opened spinal cords are inherent and the infiltrated macrophages are very rare. Following SCI, the number of infiltrated macrophages and local microglia increases significantly and the state is activated, and the local-activated microglia are dominant. After CRID3 treatment, the number and proportion of activated microglia decreases significantly.

To further clarify the effect of CRID3 on M1 and M2 cell subsets, we continued the strategy of combination of IHF and FCM. When IHF was used to distinguish M1 and M2 cell subsets, CD68, a common marker of activated macrophages and/or microglia, as well as M1(CCR7) and M2- (Arg1) specific markers [33] were detected. As shown in Fig. 4, $\mathrm{CD}^{+} 8^{+} \mathrm{CCR} 7^{+}$cells are M1 cells (a-c), CD68 ${ }^{+}$Arg1 ${ }^{+}$cells are M2 cells (d-f). $\mathrm{CD} 68^{+} \mathrm{CCR} 7^{+}$cells were very rare in sham group (a and 

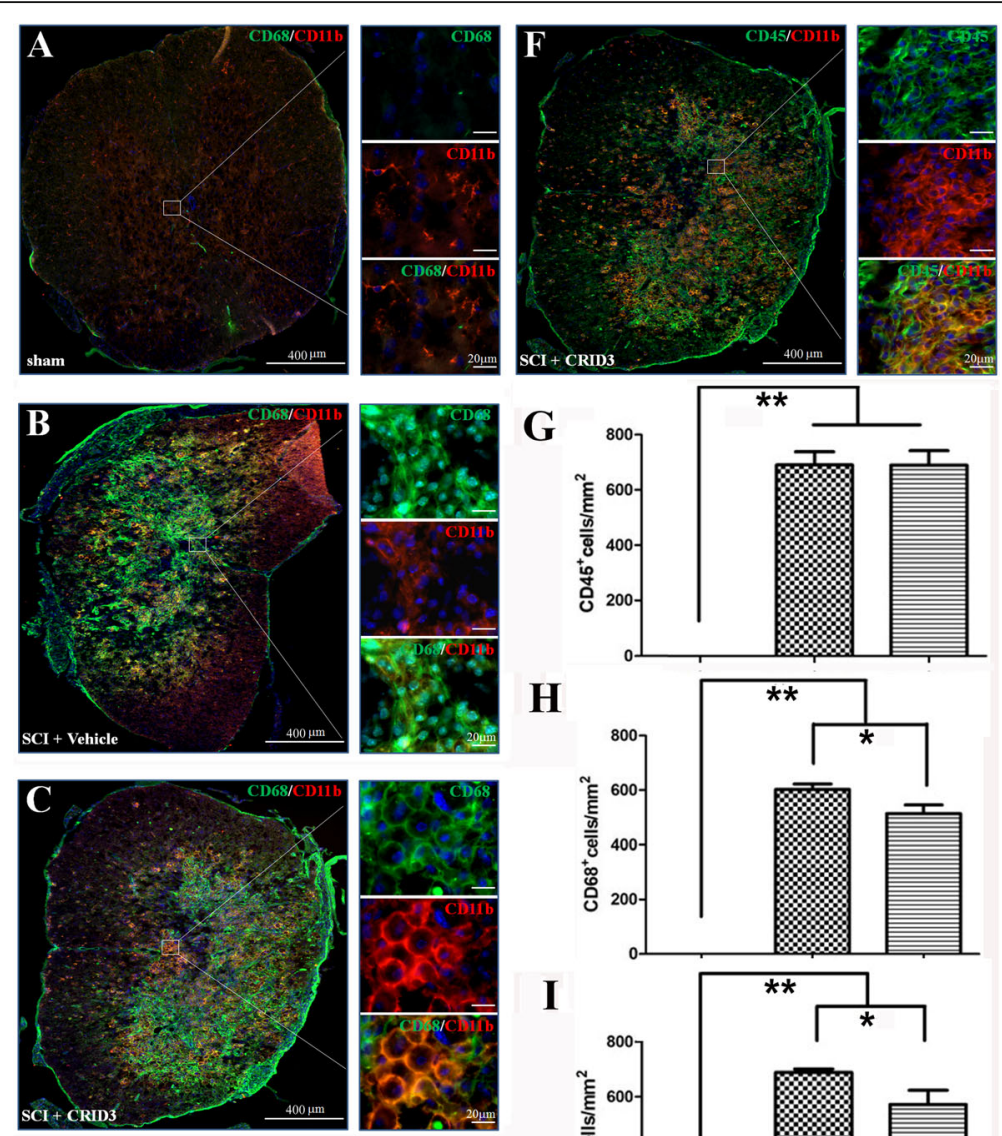

\section{$\mathbf{H}$}
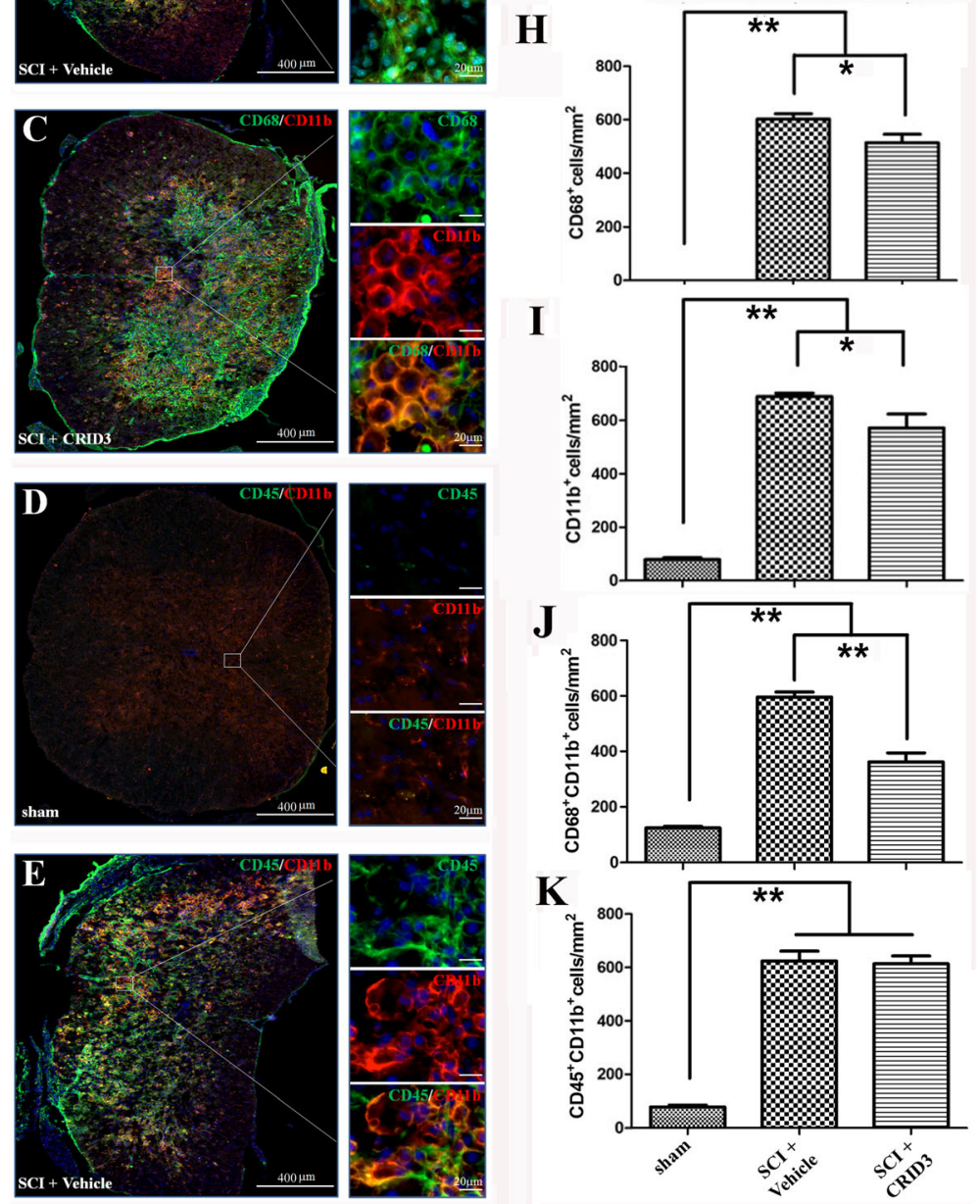

Fig. 2 Effect of CRID3 on the number and status of microglia and infiltrated macrophages in the injured spinal cord as distinguished by IHF. (a-f) Representative images of CD11b (red) and CD68 (green) (a-c) or CD45 (e-f) expression in the spinal cords in sham, SCI (vehicle), and SCl (CRID3) groups. Cells were counterstained with Hoechst 33342 (blue) to visualize nuclei. (g-k) Quantitative analysis of CD45 $(\mathbf{g}), \mathrm{CD}^{+} 8^{+}(\mathbf{h}), \mathrm{CD}_{11} \mathrm{~b}^{+}(\mathbf{i})$, $\mathrm{CD}_{68}{ }^{+} \mathrm{CD} 11 \mathrm{~b}^{+}(\mathbf{j})$, and $\mathrm{CD}_{4} 5^{+} \mathrm{CD} 11 \mathrm{~b}^{+}(\mathbf{k})$ cells in the indicated groups. Data represent the mean $\pm \mathrm{SD}(n=6)$. ${ }^{*} P<0.05$, ${ }^{* *} P<0.01$ (nonparametric Kruskal-Wallis ANOVA, followed by individual Mann-Whitney $U$ tests) 

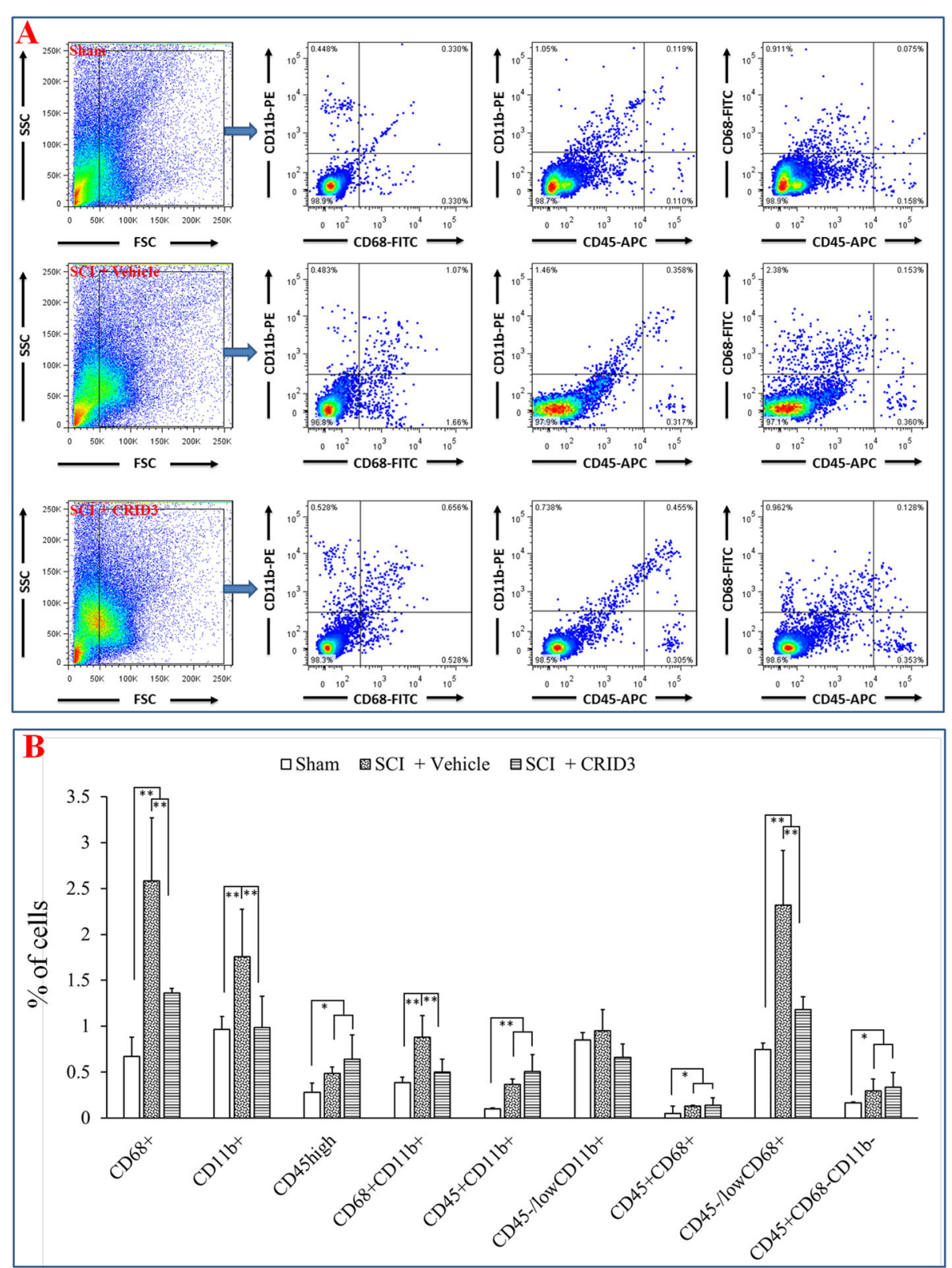

Fig. 3 Effect of CRID3 on the number and status of microglia and infiltrated macrophages in the injured spinal cord as distinguished by FCM. a Representative images of FCM in the spinal cords in sham, SCI (vehicle), and SCI (CRID3) groups. In the FSC/SSC pseudocolor plot, the same size "region" of the nucleated cells was set for each sample, and then analyze the proportion of each cell population. b Quantitative analysis of the indicated cells in the indicated groups. Data represent the mean $\pm \mathrm{SD}(n=6) .{ }^{*} P<0.05,{ }^{* *} P<0.01$ (non-parametric Kruskal-Wallis ANOVA, followed by individual Mann-Whitney $U$ tests)

g), increased significantly in SCI (vehicle) group (b and $\mathrm{g}, P<0.01, n=6)$, and decreased significantly in SCI (CRID3) group (c and g, $P<0.05, n=6$ ). ${\mathrm{CD} 68^{+} \mathrm{Arg} 1^{+}}^{+}$ cells were also very rare in the sham group $(\mathrm{d}$ and $\mathrm{h})$, increased significantly in SCI (vehicle) group (e and h, $P<0.01$, $n=6$ ), and further increased significantly in SCI (CRID3) group (f and h, $P<0.05, n=6$ ).

When FCM was used to analyze M1 and M2 cells, we used a panel of CD68, CD45, CD11b, and CCR7 [31-33]. We

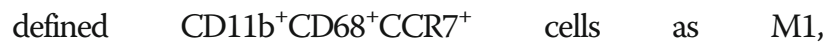

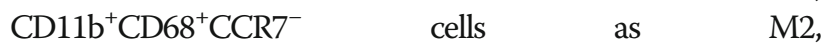
$\mathrm{CD} 45^{\text {high }} \mathrm{CD} 11 \mathrm{~b}^{+} \mathrm{CD} 68^{+} \mathrm{CCR} 7^{+}$cells as peripheral-infiltrating $\mathrm{M} 1, \mathrm{CD} 45^{\text {high }} \mathrm{CD} 11 \mathrm{~b}^{+} \mathrm{CD} 68^{+} \mathrm{CCR} 7^{-}$as peripheral-infiltrating $\mathrm{M} 2, \mathrm{CD} 5^{- \text {low }} \mathrm{CD} 11 \mathrm{~b}^{+} \mathrm{CD} 68^{+} \mathrm{CCR} 7^{+}$cells as microglia-

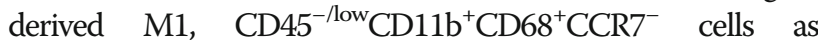
microglia-derived M2. As shown in Fig. 5a, in the CD11b/ SSC pseudocolor plots, we set the same size "region" of the nucleated $\mathrm{CD}_{11 \mathrm{~b}^{+}}$cells for each sample, and then analyzed 

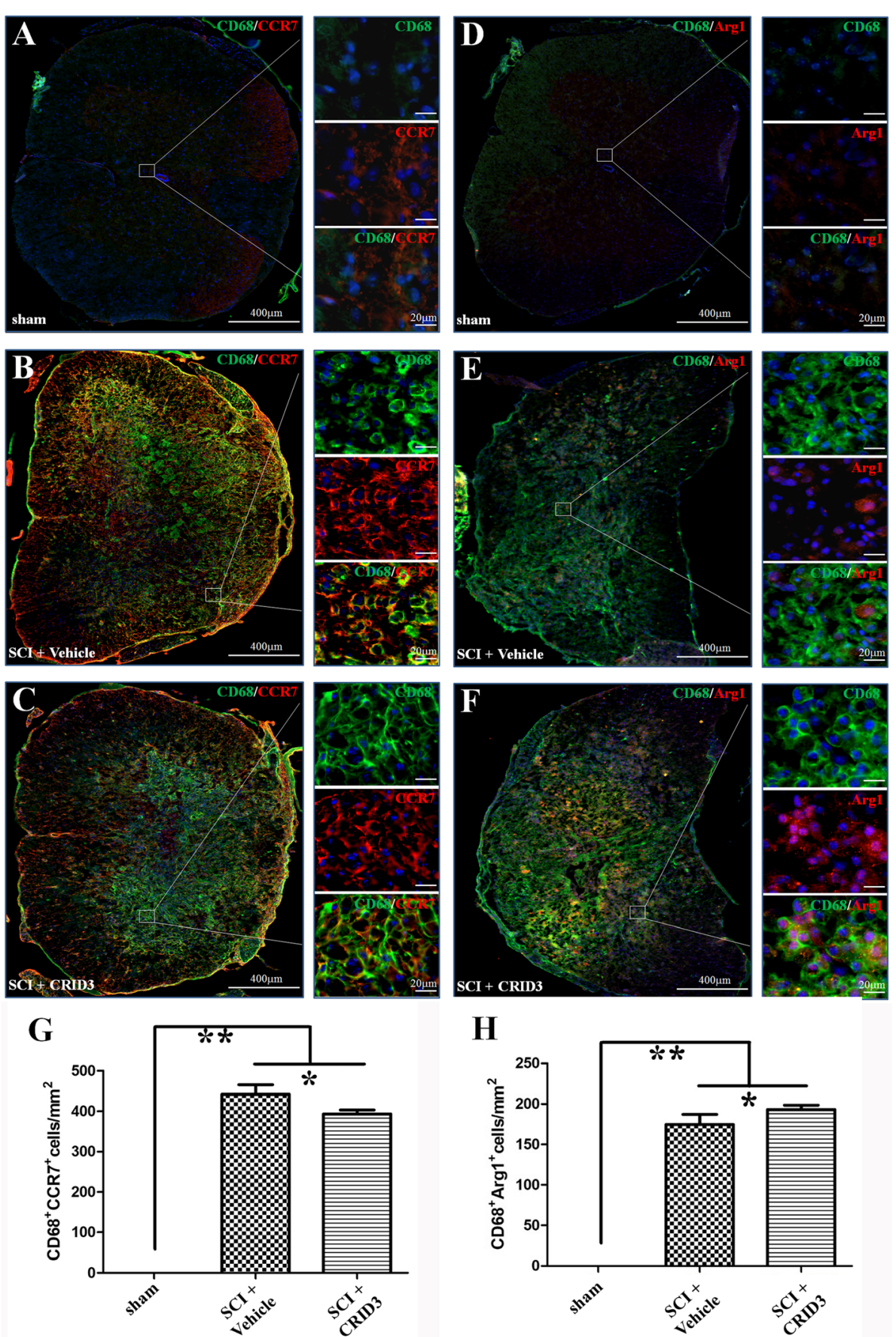

Fig. 4 Effect of CRID3 on M1 and M2 cells in the injured spinal cord as distinguished by IHF. (a-f) Representative images of CD68 (green) and CCR7 (red) (a-c) or Arg1 (e-f) expression in the spinal cords in sham, SCI (vehicle), and SCI (CRID3) groups. Cells were counterstained with Hoechst 33342 (blue) to visualize nuclei. ( $\mathbf{g}$ and $\mathbf{h}$ ) Quantitative analysis of $\mathrm{CD} 68^{+} \mathrm{CCR} 7^{+}(\mathbf{g})$ and $\mathrm{CD} 8^{+} \mathrm{Arg}^{+}$(h) cells in the indicated groups. Data represent the mean $\pm \mathrm{SD}(n=6) .{ }^{*} P<0.05,{ }^{*} P<0.01$ (non-parametric Kruskal-Wallis ANOVA, followed by individual Mann-Whitney $U$ tests)

the proportion of each cell population in CD68/CCR7 and CD45/CD11b pseudocolor plots, respectively. In the CD45/ CD11b pseudocolor plots, the "regions" of the

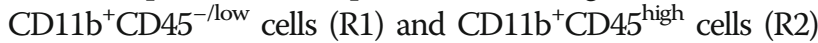
for each sample were further analyzed for the proportion of each cell population in CD68/CCR7. The statistical results of
Fig. $5 \mathrm{~b}$ showed that the proportions of $\mathrm{CD} 11 \mathrm{~b}^{+} \mathrm{CD} 68^{+} \mathrm{CCR} 7^{+}$,

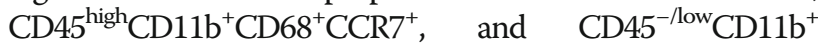
$\mathrm{CD} 8^{+} \mathrm{CCR} 7^{+}$cells in SCI (vehicle) group were significantly increased compared with sham group (all $P<0.01, n=6$ ). CRID3 could significantly inhibit the proportions of

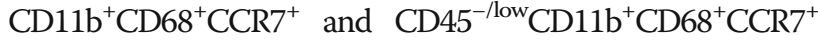



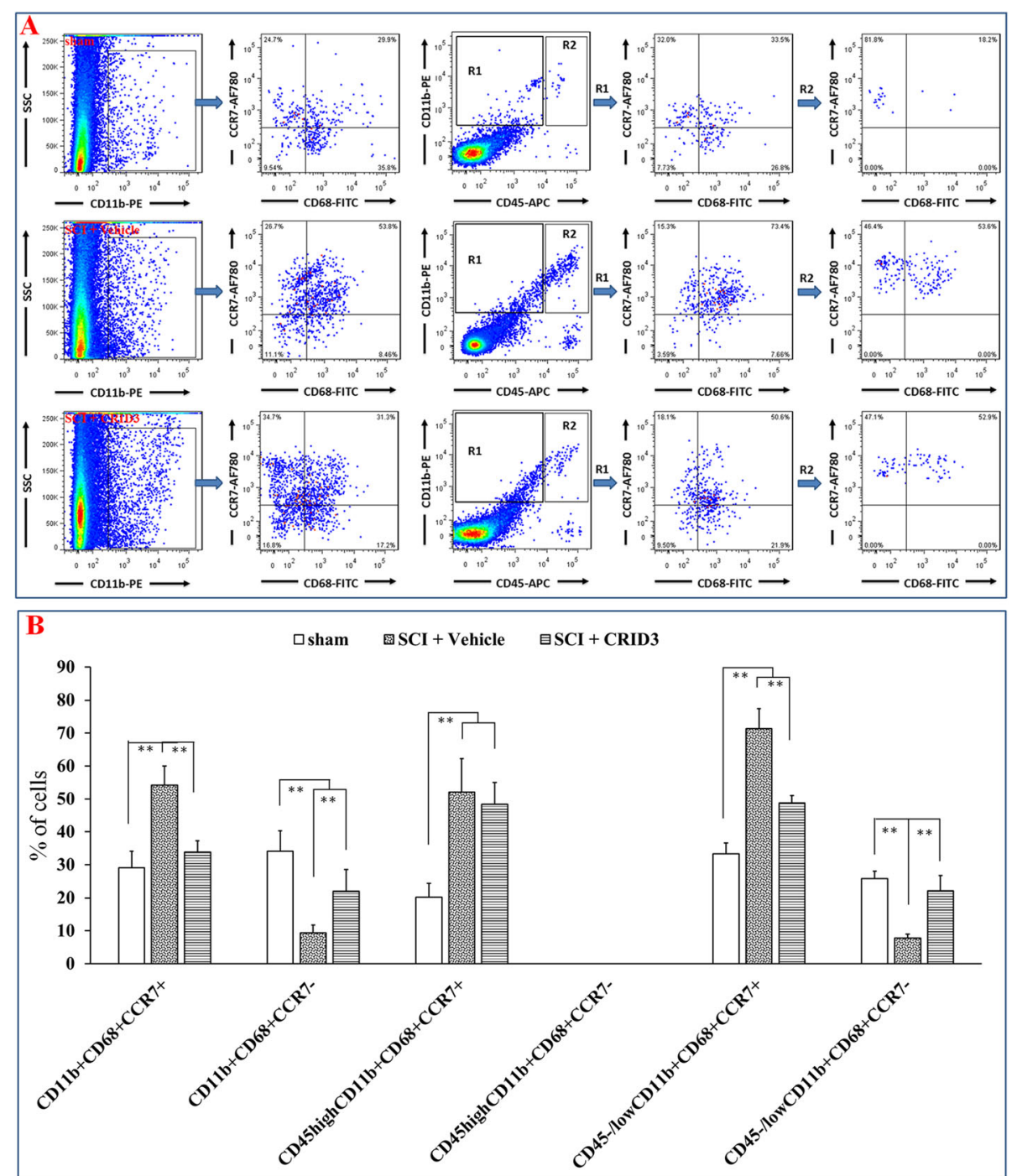

Fig. 5 Effect of CRID3 on M1 and M2 cells in the injured spinal cord as distinguished by FCM. a Representative images of FCM in the spinal cords in sham, SCI (vehicle), and SCI (CRID3) groups. In the CD11b/SSC pseudocolor plots, the same size "region" of the nucleated CD11 b ${ }^{+}$cells was set for each sample, and then analyzed the proportion of each cell population in CD68/CCR7 and CD45/CD11b pseudocolor plots, respectively. In

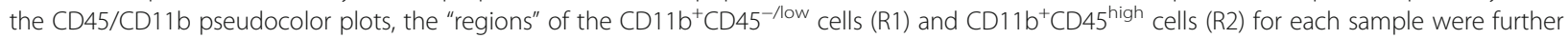
analyzed for the proportion of each cell population in CD68/CCR7. b Quantitative analysis of the indicated cells in the indicated groups. Data represent the mean \pm SD $(n=6) .{ }^{* *} P<0.01$ (non-parametric Kruskal-Wallis ANOVA, followed by individual Mann-Whitney $U$ tests)

cells (both $P<0.01, n=6$ ); however, it has no influence on $\mathrm{CD}_{4} 5^{\text {high }} \mathrm{CD} 11 \mathrm{~b}^{+} \mathrm{CD} 8^{+} \mathrm{CCR} 7^{+}$cells $(P>0.05, n=6)$. The proportions of $\mathrm{CD} 11 \mathrm{~b}^{+} \mathrm{CD} 68^{+} \mathrm{CCR} 7^{-}$and $\mathrm{CD} 45^{-/{ }^{l o w}} \mathrm{CD} 11 \mathrm{~b}^{+} \mathrm{CD} 68^{+} \mathrm{CCR} 7^{-}$cells in the two SCI groups were significantly decreased compared with the sham group (both $P<0.01, n=6$ ). However, their proportions significantly increased following CRID3 treatment (both $P<0.01, n$ = 6). $\mathrm{CD}_{4} 5^{\text {high }} \mathrm{CD} 11 \mathrm{~b}^{+} \mathrm{CD} 68^{+} \mathrm{CCR}^{-}$cells were not detected in all groups.

The results of IHF and FCM suggest that there are few macrophages infiltrating into the normal spinal cord, the local microglia have both M1 and M2 types, and the proportion is balanced. After SCI, the infiltrated macrophages increase and mainly belong to M1 type, and most of local microglia transform into M1 type. CRID3 has no significant influence on the number and differentiation of infiltrated macrophages. However, as for the phenotype transformation of local microglia following SCI, CRID3 can not only significantly inhibit microglia transform into M1 but also promote them transform into M2 cells. Here, it should be emphasized that M1 cells derived from microglia might play more important roles than those derived from macrophages in the secondary inflammatory response following SCI. 
CRID3 inhibits SCl-induced Th1 and Th1Th17 differentiation and promotes Th2 differentiation

To further clarify the effect of CRID3 on Th cell subsets, we continue the strategy of combination of IHF and FCM. When IHF was used to distinguish among different Th subsets, a general marker (CD4) [37], as well as Th1- (T-bet), Th2- (GATA3), and Th17- (ROR $\gamma$-t) [38, 39] were detected. As shown in Fig. 6, CD $4^{+}$T-bet $^{+}$cells are Th1 cells $(\mathrm{a}-\mathrm{c}), \mathrm{CD} 4^{+} \mathrm{GATA}^{+}$cells are Th2 cells (eg), CD4 $4^{+} \mathrm{ROR} \gamma-\mathrm{t}^{+}$cells are Th17 cells (i-k). All of these cells were very rare in the sham group (a, e, and $\mathrm{i})$, increased significantly in SCI (vehicle) group (b, d, f, h, j, and 1 , all $P<0.01, n=6$ ). In SCI (CRID3) group, $\mathrm{CD} 4^{+} \mathrm{T}$-bet ${ }^{+}$cells decreased significantly (c and d, $P<0.05$, $n=6$ ). However, the numbers of $\mathrm{CD} 4^{+} \mathrm{GATA}^{+}$and $\mathrm{CD} 4^{+}$ ROR $\gamma-\mathrm{t}^{+}$cells in SCI (vehicle) and SCI (CRID3) groups had no significant differences (g, h, k, and l, both $P>0.05$, $n=6)$.

When FCM was used to analyze Th cell subsets in the injured spinal cords, we used a panel of CD3, CD4, CD183, and CD196 [40-44]. Based on the previous reports, we defined $\mathrm{CD}^{+} \mathrm{CD} 4^{+} \mathrm{CD} 183^{+} \mathrm{CD} 196^{-}$cells as Th1, $\mathrm{CD}^{+} \mathrm{CD}^{+} \mathrm{CD} 183^{+} \mathrm{CD} 196^{+}$cells as Th1Th17, $\mathrm{CD}^{+} \mathrm{CD} 4^{+} \mathrm{CD} 183^{-} \mathrm{CD} 196^{+}$cells as Th17, and $\mathrm{CD}^{+}{ }^{+} \mathrm{CD} 4^{+} \mathrm{CD} 183^{-} \mathrm{CD} 196^{-}$cells as Th2. As shown in
Fig. 7a, in the FSC/SSC pseudocolor plot, we set the same size "region" of lymphocytes for each sample, and then analyzed the proportion of each Th subsets in the "region" of $\mathrm{CD}^{+} \mathrm{CD}^{+}$in $\mathrm{CD} 3 / \mathrm{CD} 4$ pseudocolor plots. The statistical results of Fig. 7b showed that the proportions of all Th subsets in SCI (vehicle) and SCI (CRID3) groups were significantly increased compared with the sham group (all $P<0.01, n=6$ ). However, $\mathrm{CD}^{+}{ }^{+} \mathrm{CD} 4^{+} \mathrm{CD} 183^{+} \mathrm{CD} 196^{+}$cells were dominant in all Th subsets, and its proportion in SCI (CRID3) group was significantly decreased compared with SCI (vehicle) group $(P<0.01, n=6)$. Although few in number, the proportion of $\mathrm{CD}^{+} \mathrm{CD} 4^{+} \mathrm{CD} 183^{-} \mathrm{CD} 196^{-}$cells in $\mathrm{SCI}$ (CRID3) group was significantly increased compared with SCI (vehicle) group $(P<0.01, n=6)$. The other two subsets had no differences between the latter two groups $(P>0.05, n=6)$, and their numbers were also very few. In addition, the numbers and proportions of regulatory $\mathrm{T}$ cell (Treg) and cytotoxic $\mathrm{T}$ cells $(\mathrm{Tc})$ have also been detected. Although they both increase significantly after SCI, CRID3 has no significant effect on their numbers and proportions (Fig. S1 and S2, both $P>0.05$, $n=6)$.

Combined with the results of IHF and FCM, it can be found that the number of Th1, Th2, and Th17 cells
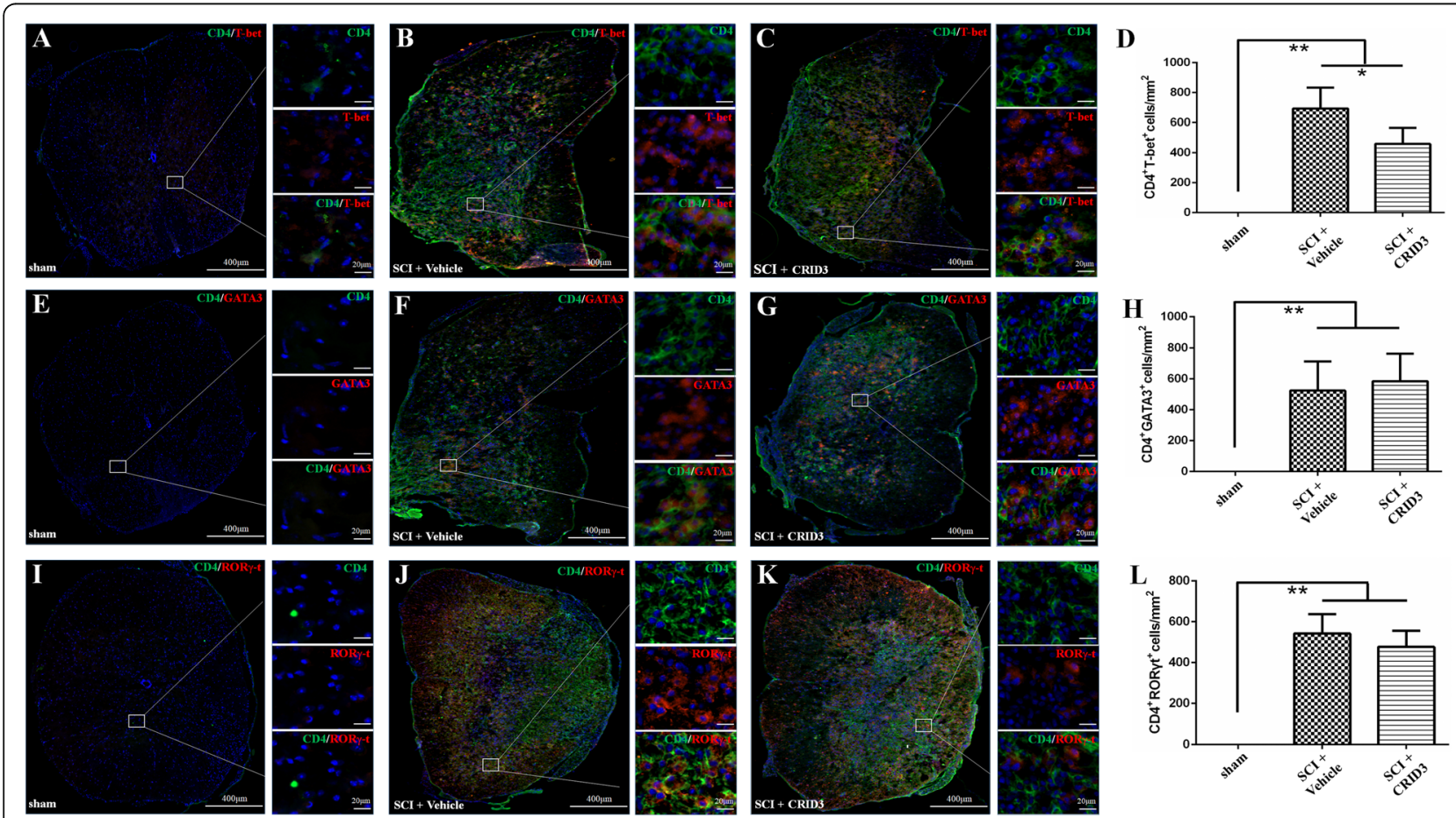

Fig. 6 Effect of CRID3 on Th1, Th2, and Th17 cells in the injured spinal cord as distinguished by IHF. (a-f) Representative images of CD4 (green) and T-bet (red) (a-c) or GATA3 (red) (e-f) or (RORy-t) (red) (i-k) expression in the spinal cords in sham, SCl (vehicle), and SCl (CRID3) groups. Cells were counterstained with Hoechst 33342 (blue) to visualize nuclei. (d, $\mathbf{h}$, and $\mathbf{I}$ ) Quantitative analysis of CD4 ${ }^{+} \mathrm{T}-$ bet $^{+}(\mathbf{d}), \mathrm{CD}^{+} \mathrm{GATA} 3^{+}(\mathbf{h})$, and $\mathrm{CD}^{+} \mathrm{RORY}_{-\mathrm{t}}{ }^{+}$(I) cells in the indicated groups. Data represent the mean $\pm \mathrm{SD}(n=6) .{ }^{*} P<0.05,{ }^{* *} P<0.01$ (non-parametric Kruskal-Wallis ANOVA, followed by individual Mann-Whitney $U$ tests) 

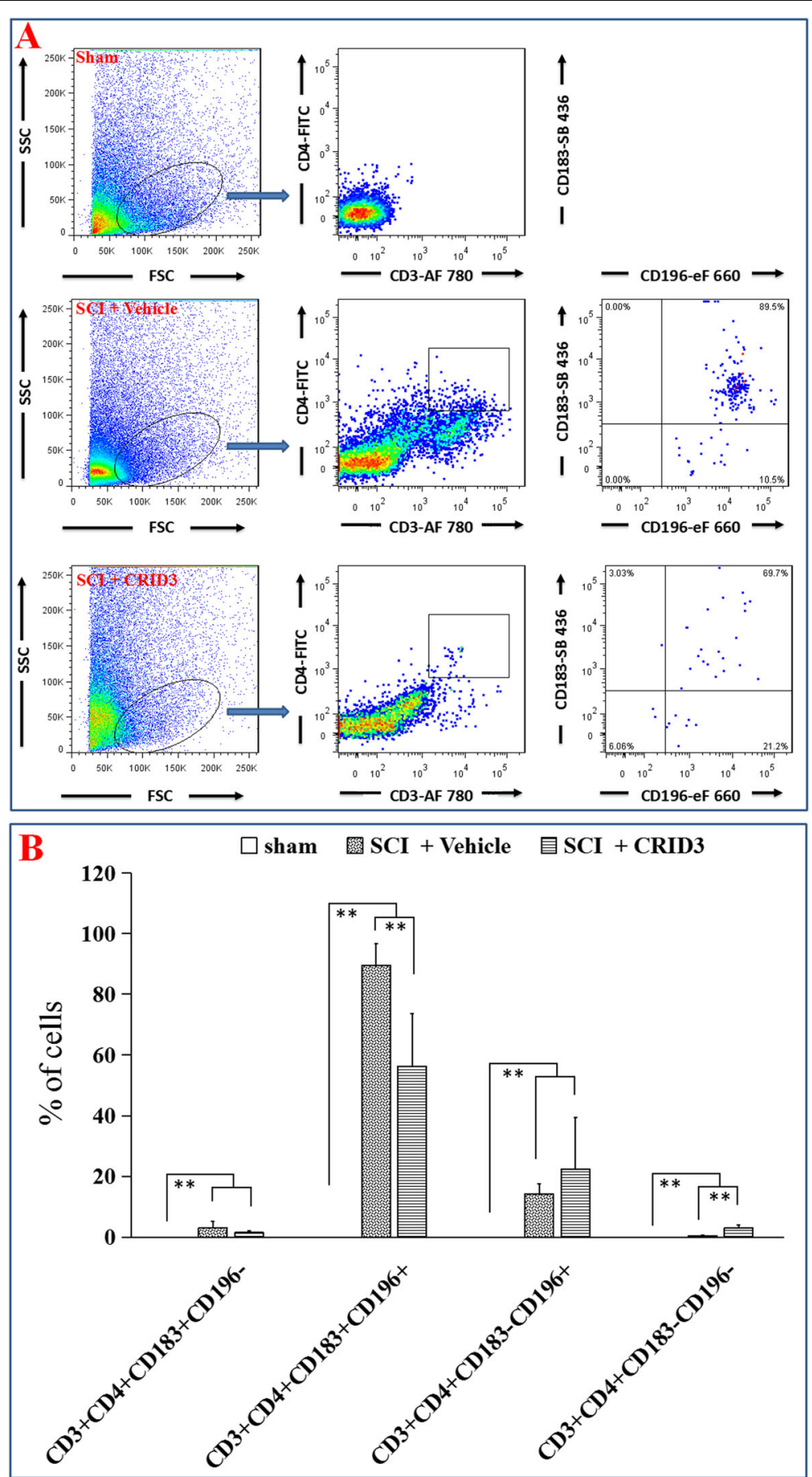

Fig. 7 Effect of CRID3 on Th1, Th2, and Th17 cells in the injured spinal cord as distinguished by FCM. a Representative images of FCM in the spinal cords in sham, SCI (vehicle), and SCI (CRID3) groups. In the FSC/SSC pseudocolor plot, the same size "region" of lymphocytes was set for each sample, and then analyzed the proportion of each Th subsets in the "region" of CD3 ${ }^{+} C D 4^{+}$in CD3/CD4 pseudocolor plots. b Quantitative analysis of the indicated cells in the indicated groups. Data represent the mean $\pm \mathrm{SD}(n=6){ }^{* *} P<0.01$ (non-parametric Kruskal-Wallis ANOVA, followed by individual Mann-Whitney $U$ tests)

increases significantly after SCI, but in proportion, Th1Th17 cell subset is dominant. CRID3 can not only reduce Th1 cell number and Th1Th17 subset proportion but also increase Th2 cell proportion. The final results should be significant inhibition of Th1 and Th1Th17 differentiation and promotion of Th2 differentiation. 
CRID3 reduces fibrosis, increases myelination and residual neurons, and promotes functional recovery

To determine the effects of CRID3 on histopathology and behavior after SCI, the fibrosis area, myelin preservation, and neuronal survival were detected by hematoxylin-eosin (HE), Luxol fast blue (LFB), and Nissl staining, respectively. Figures $8 \mathrm{a}$ and $9 \mathrm{a}$ are the representative pictures of $\mathrm{HE}$ and LFB staining in the transverse sections of injured center of spinal cords and the corresponding sections of sham-opened spinal cords. Figure $8 \mathrm{~b}$ showed that the fibrosis areas at the lesion epicenter, $0.25 \mathrm{~mm}$ rostral and caudal, and $0.5 \mathrm{~mm}$ rostral to the epicenter in SCI (CRID3) group were smaller than those of SCI (vehicle) group $(P<0.01$ or $0.05, n=10)$. Figure $9 \mathrm{~b}$ showed that the LFB-positive areas at the lesion epicenter and $0.25 \mathrm{~mm}$ rostral and caudal to the epicenter of SCI (CRID3) group were larger than those of SCI (vehicle) group $(P<0.01$ or $0.05, n=10)$. Figure $10 \mathrm{a}$ is the representative picture of Nissl staining in the transverse sections at $1 \mathrm{~mm}$ rostral to the injured epicenter and the corresponding section of sham-opened spinal cord. Figure $10 \mathrm{~b}$ showed that the numbers of residual ventral horn motoneurons at 0.5 and
$1 \mathrm{~mm}$ rostral and caudal to the epicenter in SCI (CRID3) group were more than those of SCI (vehicle) group $(P<$ $0.05, n=10)$.

To investigate the effect of CRID3 on behavior recovery following SCI, the BMS scores were evaluated at 1 and 3 days, then 1, 2, 3, 4, 5-, and 6-weeks post-injury. As shown in Fig. 11, the scores of sham group and preinjury were all 9 points, and there were no significant differences between SCI (CRID3) and SCI (vehicle) group from 1 day to 21 days post-injury (dpi). At 28, 35 and $42 \mathrm{dpi}$, the scores in SCI (CRID3) group were increased compared with SCI (vehicle) group. There were significant differences between the two groups $(P<0.05$, $n=10)$.

\section{Discussion}

Inflammasome is a multiprotein complex, which can regulate caspase- 1 activation and promote the maturation and secretion of IL-1 $\beta$ and IL-18 in the process of natural immune defense $[45,46]$. It can also regulate pyroptosis and induce cell death under inflammatory and stress conditions [45-48]. Inflammasomes have
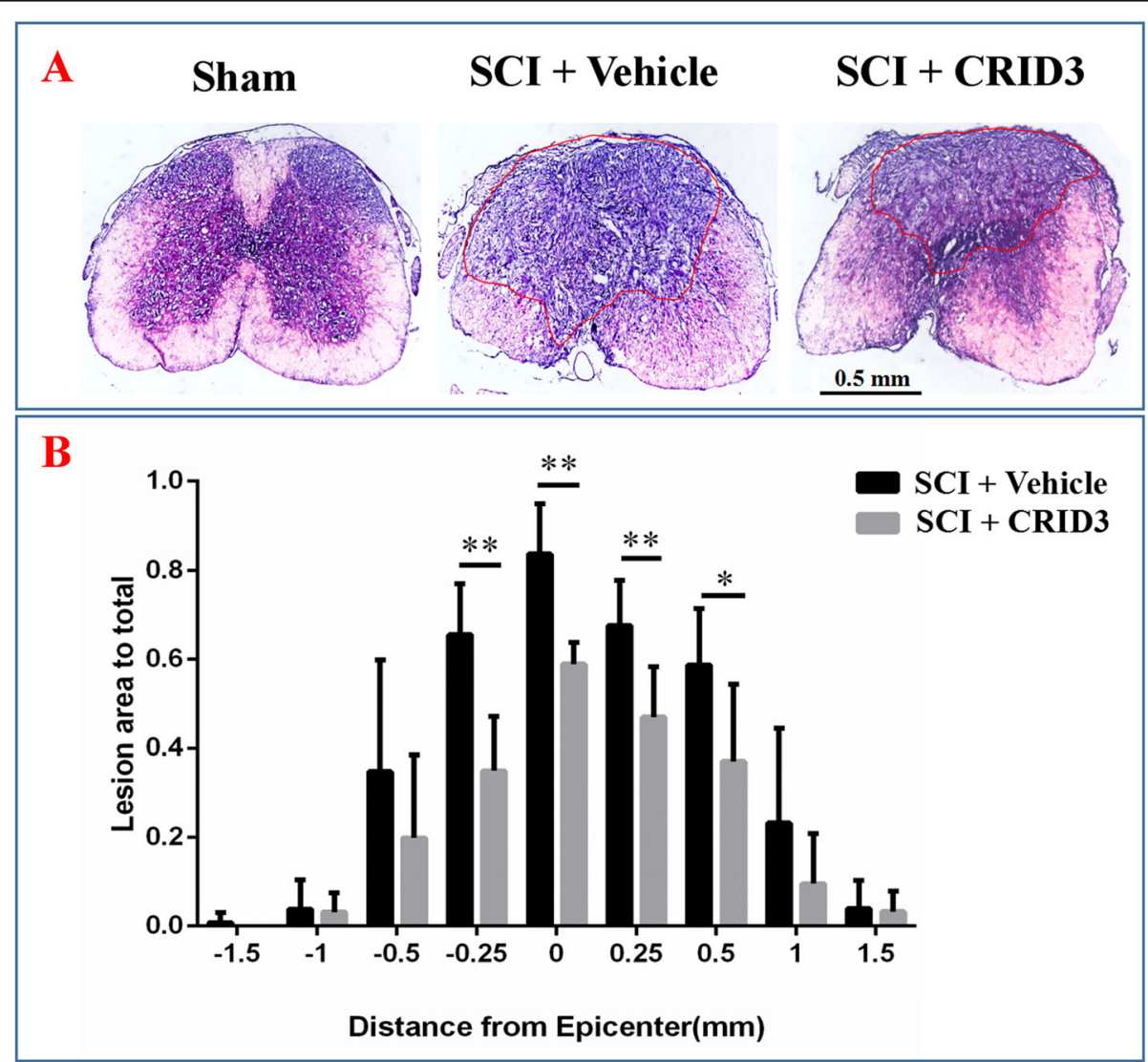

Fig. 8 Quantitative analysis of the effect of CRID3 on fibrosis area 6 weeks after SCl. a HE-stained spinal cord cross section from the injury epicenter and the corresponding sections of sham-opened spinal cord. $\mathbf{b}$ Quantitative analysis of fibrosis area in different groups at various distances from the injury epicenter $(0)$ and $0.25,0.5,1$, and $1.5 \mathrm{~mm}$ rostral $(+)$ and caudal $(-)$ to the epicenter. Data represent the mean \pm SD $(n=$ 10). ${ }^{*} P<0.05,{ }^{*} P<0.01$ (repeated measures two-way ANOVA, followed by post hoc analysis for multiple comparisons) 


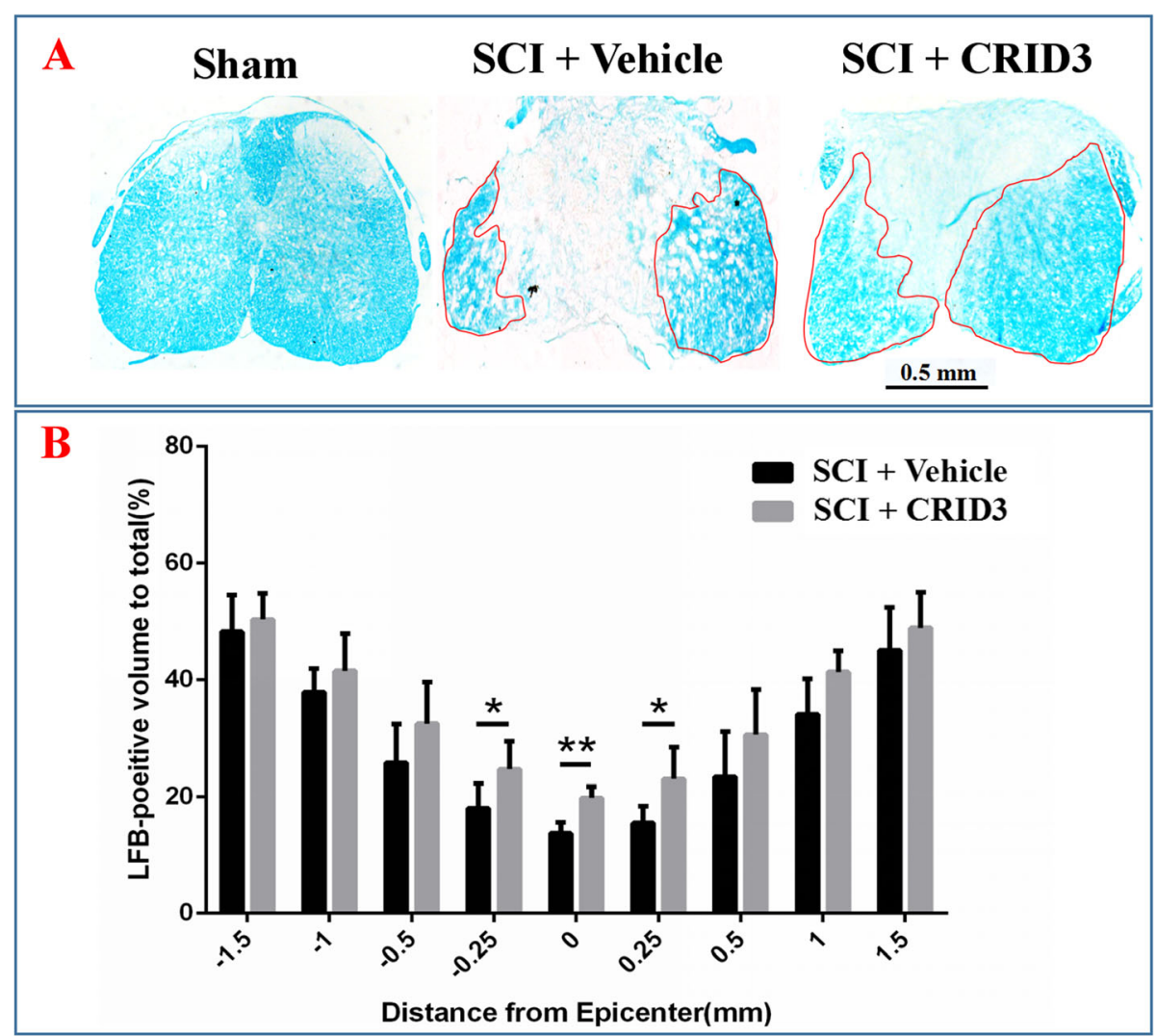

Fig. 9 Quantitative analysis of the effect of CRID3 on residual myelination 6 weeks after SCI. a LFB-stained spinal cord cross section from the injury epicenter and the corresponding sections of sham-opened spinal cord. $\mathbf{b}$ Quantitative analysis of residual myelination in different groups at various distances from the injury epicenter $(0)$ and $0.25,0.5,1$, and $1.5 \mathrm{~mm}$ rostral $(+)$ and caudal $(-)$ to the epicenter. Data represent the mean \pm $\mathrm{SD}(n=10) .{ }^{*} P<0.05,{ }^{* *} P<0.01$ (repeated measures two-way ANOVA, followed by post hoc analysis for multiple comparisons)

been reported to be involved in many diseases, including atherosclerosis [49], type II diabetes [50], Alzheimer's disease [51], and autoimmune diseases [52]. Some inflammasomes, such as NLRP1, NLRP2, NLRP3, and AIM2, have been demonstrated play important roles in the inflammation of CNS injury [53, 54]. Although there are many different inflammasomes, ASC is their common adaptor protein [55]. Therefore, we speculate that ASC can be used as a target to inhibit the activation of inflammasomes, so as to improve the local immune microenvironment of SCI and reduce nerve damage. Previous studies have identified that CRID3 can inhibit ASC oligomerization in response to the stimulation of inflammasomes and further inhibit caspase-1 processing, IL-1 $\beta$ secretion, and pyroptosis in murine models of traumatic brain injury, dermal and pulmonary inflammation $[18,56,57]$. Our WB results also show that CRID3 can inhibit ASC expression and the activation of its related molecules, such as caspase-1, IL-1 $\beta$, and IL-18, following SCI. Therefore, our study demonstrates that CRID3 can also affect the expression of inflammasome downstream inflammatory factors by inhibiting ASC oligomerization in the murine model of SCI.

Following SCI, inflammation is characterized by activated and increased inflammatory cells in the injured area, resulting in production of inflammatory factors, formation of inflammatory microenvironment, and eventually dysfunction [6]. Previous studies have shown that under natural conditions, the local immune microenvironment of SCI is "Yin-Yang" imbalance, and inflammatory cell subsets (such as Th1, Th17, Tc, and M1) and factors (such as IL- $1 \beta$, IL-18, IL- 6 , IFN- $\gamma$, and TNF- $\alpha$ ) are dominant, while anti-inflammatory cell subsets (such as Th2, Treg, Ts, and M2) and factors (such as IL-4, -10, -13 , and TGF- $\beta$ ) are very rare $[5,6,58-62]$. This is an important mechanism of pathological damage following SCI. Since CRID3 can inhibit ASC and reduce the production of IL-1 $\beta$ and IL-18, we speculate that CRID3 can also improve the local immune microenvironment and play a neuroprotective role.

To clarify the effect of CRID3 on immune cell subsets, we used the strategy of combination of IHF and FCM. 

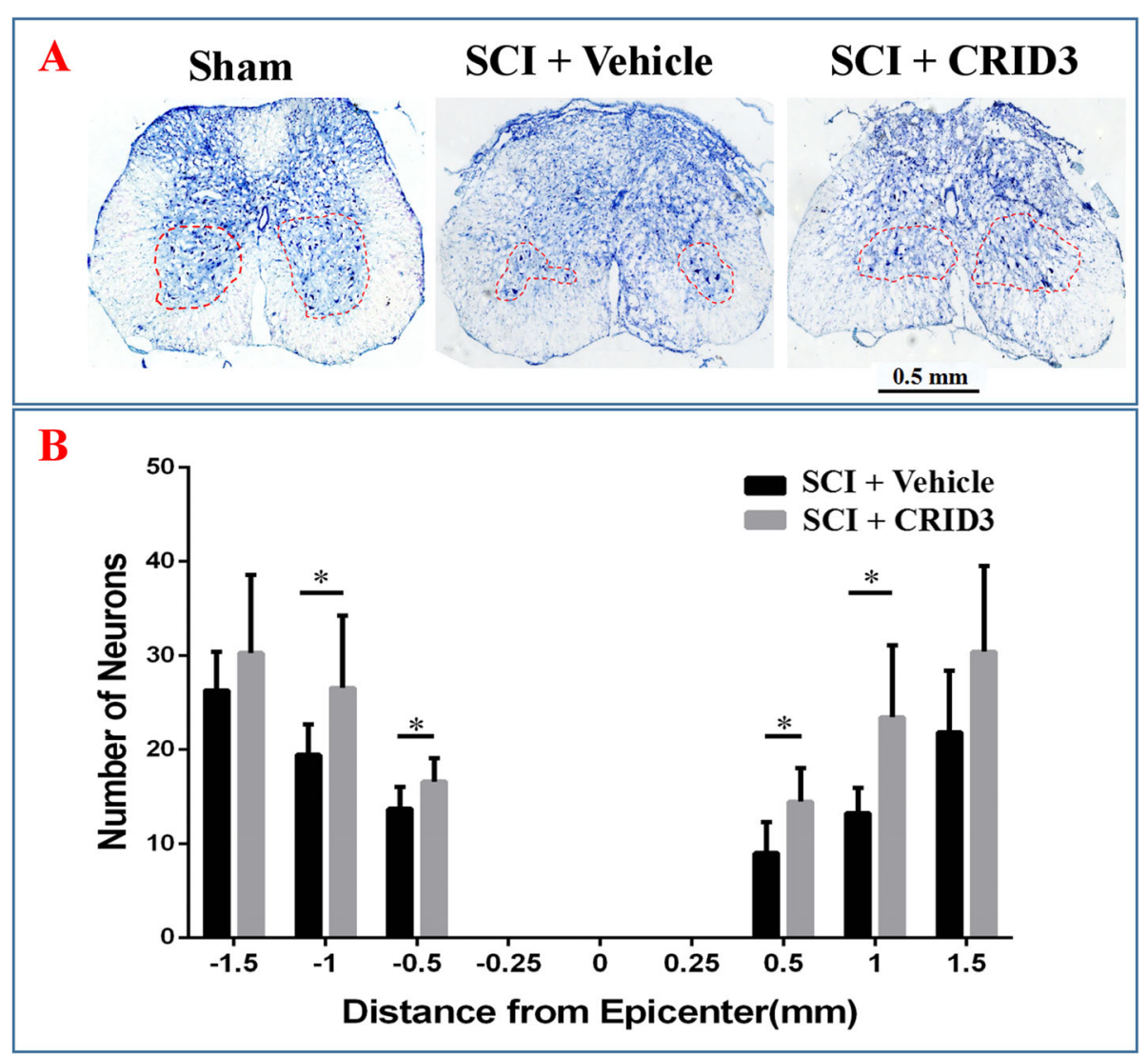

Fig. 10 Quantitative analysis of the effect of CRID3 on motor neuron survival 6 weeks after SCI. a Nissl-stained spinal cord cross section from 0.5 $\mathrm{mm}$ rostral to the epicenter and the corresponding sections of sham-opened spinal cord. $\mathbf{b}$ Quantitative analysis of residual ventral horn motoneurons in different groups at various distances from the injury epicenter $(0)$ and $0.25,0.5,1$, and $1.5 \mathrm{~mm}$ rostral $(+)$ and caudal $(-)$ to the epicenter. Data represent the mean $\pm \mathrm{SD}(n=10)$. ${ }^{*} P<0.05$ (repeated measures two-way ANOVA, followed by post hoc analysis for multiple comparisons)

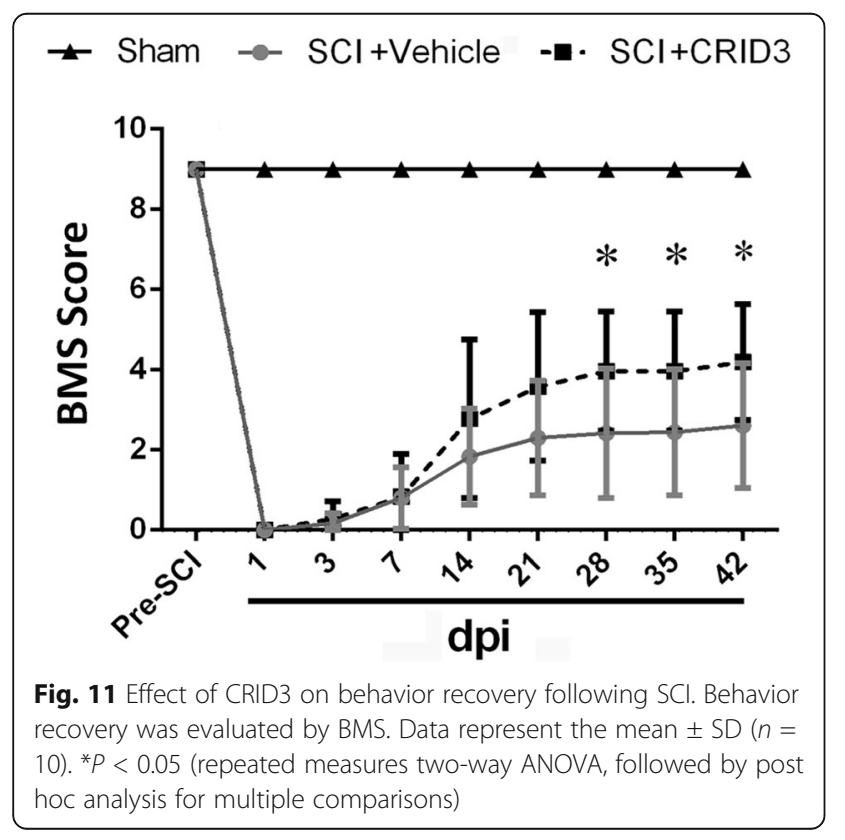

To distinguish among peripheral infiltrated leukocytes, infiltrated macrophages and local microglia, CD45, a general marker of leukocytes [30, 31], CD11b, the common marker of macrophages and microglia [32], CD68, a common marker of activated macrophages and/or microglia [33, 34], and M1- (CCR7) and M2- (Arg1) specific markers [33] were detected. The results indicate that the microglia in the sham-opened spinal cords are inherent, including both M1 and M2 subtypes and the proportion is balanced; however, the infiltrated macrophages are very rare. Following SCI, the infiltrated macrophages increase and mainly belong to M1 type, and most of the local microglia transform into M1 type. CRID3 has no significant influence on the number and differentiation of infiltrated macrophages. However, as for the phenotype transformation of local microglia, CRID3 can not only significantly reduce M1 cells but also increase M2 cells following SCI. So, we speculated that microglia-derived M1 cells might play more important roles than those derived from macrophages following $\mathrm{SCI}$ and microglia are more likely to be the target cells 
of CRID3. This is consistent with the recent reports, which demonstrated that inhibiting inflammasome activation can diminish M1 microglia and improve M2 microglia in vivo and in vitro [63-65]. However, its effect on other immune cell subsets still needs to be further explored.

To distinguish among different Th subsets, a general marker (CD4) [37], as well as Th1- (T-bet), Th2(GATA3), and Th17- (ROR $-\mathrm{t}$ ) specific markers [38, 39] were detected by IHF. We found that the number of Th1, Th2, and Th17 cells increase significantly following SCI, CRID3 can reduce the number of Th1 cells; however, it has no influence on Th2 and Th17 cells. To analyze the proportion of Th cell subsets, FCM was used. In vitro, the classical FCM method to detect Th subsets is to activate $\mathrm{T}$ cells with stimulus, and then detect their general markers (CD3 and CD4) [66], as well as Th1- (INF- $\gamma$ ), Th2- (IL-4), and Th17- (IL-17) specific cytokines [67, 68]. However, in the injured spinal cords, it is impossible to apply the same method as in vitro. To solve this problem, we used a panel of surface markers which include CD3, CD4, CD183 (CXCR3), and CD196 (CXR6). Here, CD3 and CD4 are general markers of Th subsets [66], CD183 is the marker of Th1 cells and CD196 is the marker of Th17 cells [42]. Based on these markers, $\mathrm{CD}^{+} \mathrm{CD} 4{ }^{+} \mathrm{CD} 183^{+} \mathrm{CD} 196^{-}$cells are Th1, $\mathrm{CD}^{+}{ }^{+} \mathrm{CD} 4^{+} \mathrm{CD}_{183}{ }^{-} \mathrm{CD} 196^{+}$cells are Th17 and $\mathrm{CD}^{+}{ }^{+} \mathrm{CD} 4^{+} \mathrm{CD} 183^{-} \mathrm{CD} 196^{-}$cells are Th2. In addition, a special group of $\mathrm{CD}^{+} \mathrm{CD} 4^{+} \mathrm{CD} 183^{+} \mathrm{CD} 196^{+}$substyle is named Th1Th17. Th1Th17 is an interesting Th subset, which can produce both Th1 and Th17 cytokines, such as IFN- $\gamma$ and IL-17 $[42,69]$. Based on its cytokines, we speculate that it is a group of Th cells with stronger inflammation. Maybe it is because of the limitation of methodology that it is difficult to detect this group of cells only by immunohistochemistry. Here, combining with FCM, we found that Th1Th17 cell subset is dominant in Th cells in the injured spinal cord. CRID3 can reduce the number of Th1 cells and increase Th2 cells. In proportion, it also decreases Th1Th17 subset. The final results should be to significantly inhibit Th1 and Th1Th17 and promote Th2 cell differentiation. In addition, the numbers and proportions of Treg and Tc have also been detected. Although they both increase significantly following SCI, CRID3 has no significant effect on their numbers and proportions. This is consistent with the recent reports, which demonstrated that inflammasome activation can destroy Th1/Th2 balance, produce predominant Th1/Th17 inflammatory response, and inhibiting inflammasome activation can restore the Th1/Th2 balance [70-72].

Taken together, CRID3 can improve the local immune microenvironment by inhibiting inflammasome activation, which consequently suppress M1 microglia, Th1 and Th1Th17 differentiation, and increase M2 microglia and Th2 differentiation. These findings support that CRID3 might provide neuroprotection and improve behavior following SCI.

To determine whether CRID3 provides neuroprotection and improves functional recovery following SCI, morphological and functional assays were performed. A significant decrease in spinal cord fibrosis area accompanied by increasing myelinated white matter and residual ventral horn motoneurons, as well as corresponding locomotor improvements, is observed upon CRID3 treatment, as compared to animals receiving vehicle treatment, demonstrating that CRID3 treatment provides neuroprotection and promotes functional recovery following SCI.

\section{Conclusions}

In conclusion, this study elucidates a mechanism by which CRID3 may ameliorate murine SCI by inhibiting inflammasome activation, reducing proinflammatory factor production, restoring immune cell subset balance, and improving local immune microenvironment, and early administration of CRID3 may be a promising therapeutic strategy for SCI.

\section{Supplementary information}

Supplementary information accompanies this paper at https://doi.org/10. 1186/s12974-020-01937-8.

Additional file 1: Figure S1. Effect of CRID3 on the numbers and proportions of Treg in the injured spinal cord. C) Representative images of CD4 (red) and FoxP3 (green) expression in the spinal cords in sham, $\mathrm{SCl}$ (vehicle) and SCI (CRID3) groups. Cells were counterstained with Hoechst 33342 (blue) to visualize nuclei. (D) Quantitative analysis of $\mathrm{CD}^{+}{ }^{+} \mathrm{FoxP}^{+}$cells in the indicated groups. Data represent the mean $\pm \mathrm{SD}$ $(n=6) .{ }^{* * P}<0.01$ (non-parametric Kruskal-Wallis ANOVA, followed by individual Mann-Whitney $U$ tests). (E) Representative images of FCM in the spinal cords in sham, SCI (vehicle) and SCI (CRID3) groups. In the FSC/SSC pseudocolor plot, the same size "region" of lymphocytes was set for each sample, and then analyzed the proportion of Treg subset in the "region" of $\mathrm{CD}^{+} \mathrm{CD}^{+}$in CD25/CD127 pseudocolor plots. (F) Quantitative analysis of the indicated cells in the indicated groups. Data represent the mean \pm SD $(n=6)$. $P>0.05$ (non-parametric Kruskal-Wallis ANOVA, followed by individual Mann-Whitney $U$ tests).

Additional file 2: Figure S2. Effect of CRID3 on the numbers and proportions of Tc in the injured spinal cord. (A-C) Representative images of CD8 (green) and CD28 (red) expression in the spinal cords in sham, $\mathrm{SCl}$ (vehicle) and SCI (CRID3) groups. Cells were counterstained with Hoechst 33342 (blue) to visualize nuclei. (D) Quantitative analysis of $\mathrm{CD}^{+}{ }^{+} \mathrm{CD} 28^{+}$cells in the indicated groups. Data represent the mean $\pm \mathrm{SD}$ $(n=6)$. ${ }^{*} P<0.01$ (non-parametric Kruskal-Wallis ANOVA, followed by individual Mann-Whitney $U$ tests). (E) Representative images of FCM in the spinal cords in sham, SCI (vehicle) and SCI (CRID3) groups. In the FSC/SSC pseudocolor plot, the same size "region" of lymphocytes was set for each sample, and then analyzed the proportion of Tc subset in the "region" of $\mathrm{CD}^{+} \mathrm{CD}^{+}$in $\mathrm{CD} 8 / \mathrm{CD} 28$ pseudocolor plots. (F) Quantitative analysis of the indicated cells in the indicated groups. Data represent the mean \pm SD $(n=6) . P>0.05$ (non-parametric Kruskal-Wallis ANOVA, followed by individual Mann-Whitney $U$ tests). 


\section{Abbreviations}

ASC: Apoptosis-associated speck-like protein containing a card; BMS: Basso mouse scale; CNS: Central nervous system; CRID3: A blocker of ASC oligomerization; DAMPs: Damage-associated molecular patterns; HE: Hematoxylin-eosin; IHF: Immunohistofluorescence; FCM: Flow cytometry; LFB: Luxol fast blue; PAMPs: Pathogen-associated molecular patterns; PFA: Paraformaldehyde; SCI: Spinal cord injury; WB: Western blot

\section{Acknowledgements}

Not applicable.

\section{Author disclosure statement}

The authors declare no competing financial interest.

\section{Authors' contributions}

HZL participated in literature search, study design, data interpretation, and writing. JGH participated in the study design and data collection. YQC, SNW, YJS, JC, SQD, and LS performed experimental procedures. JT, RW, and HD conducted data analysis and figures. All authors read and approved the final manuscript.

\section{Funding}

This study was supported by grants from the National Natural Science Foundation of China (81772321)

\section{Availability of data and materials}

The datasets used and/or analyzed during the current study are available from the corresponding author on reasonable request.

\section{Ethics approval and consent to participate}

All surgical procedures and postoperative animal care were in accordance with the Regulations for the Administration of Affairs Concerning Experimental Animals (Ministry of Science and Technology, China; revised in June 2004) and the Guidelines and Policies for Rodent Survival Surgery provided by the Animal Care and Use Committees of Bengbu Medical College (Ethical approval number: 2017-037).

\section{Consent for publication}

Not applicable.

\section{Competing interests}

The authors declare that they have no competing interests.

\section{Author details}

${ }^{1}$ Clinical Laboratory, The First Affiliated Hospital of Bengbu Medical College, 233004 Bengbu, Anhui, People's Republic of China. ${ }^{2}$ Anhui Key Laboratory of Tissue Transplantation, The First Affiliated Hospital of Bengbu Medical College, 287 Chang Huai Road, Bengbu 233004, Anhui, People's Republic of China. ${ }^{3}$ Department of Immunology, Bengbu Medical College, 233030 Bengbu, Anhui, People's Republic of China. ${ }^{4}$ Anhui Key Laboratory of Infection and Immunity, Bengbu Medical College, 233030 Bengbu, Anhui, People's Republic of China.

\section{Received: 7 April 2020 Accepted: 20 August 2020}

Published online: 29 August 2020

\section{References}

1. Rubiano AM, Carney N, Chesnut R, Puyana JC. Global neurotrauma research challenges and opportunities. Nature. 2015;527:S193-7.

2. Singh A, Tetreault L, Kalsi-Ryan S, Nouri A, Fehlings MG. Global prevalence and incidence of traumatic spinal cord injury. Clin Epidemiol. 2014:6:309-31.

3. Hayta E, Elden H. Acute spinal cord injury: a review of pathophysiology and potential of non-steroidal anti-inflammatory drugs for pharmacological intervention. J Chem Neuroanat. 2018:87:25-31.

4. Rouanet C, Reges D, Rocha E, Gagliardi V, Silva GS. Traumatic spinal cord injury: current concepts and treatment update. Arq Neuropsiquiatr. 2017;75: 387-93.

5. Ahmed A, Patil AA, Agrawal DK. Immunobiology of spinal cord injuries and potential therapeutic approaches. Mol Cell Biochem. 2018;441:181-9.
6. Sun X, Jones ZB, Chen XM, Zhou L, So KF, Ren Y. Multiple organ dysfunction and systemic inflammation after spinal cord injury: a complex relationship. J Neuroinflammation. 2016;13:260.

7. Martinon F, Burns K, Tschopp J. The inflammasome: a molecular platform triggering activation of inflammatory caspases and processing of prolL-beta. Mol Cell. 2002;10:417-26.

8. Jamilloux Y, Martinon F. Cell-free assay for inflammasome activation. Methods Mol Biol. 2016;1417:207-15.

9. Christgen S, Place DE, Kanneganti TD. Toward targeting inflammasomes: insights into their regulation and activation. Cell Res. 2020.

10. Sharma D, Kanneganti TD. The cell biology of inflammasomes: mechanisms of inflammasome activation and regulation. J Cell Biol. 2016:213:617-29.

11. Latz E, Xiao TS, Stutz A. Activation and regulation of the inflammasomes. Nat Rev Immunol. 2013;13:397-411

12. de Rivero Vaccari JP, Dietrich WD, Keane RW. Therapeutics targeting the inflammasome after central nervous system injury. Transl Res. 2016;167:35-45.

13. Kigerl KA, de Rivero Vaccari JP, Dietrich WD, Popovich PG, Keane RW. Pattern recognition receptors and central nervous system repair. Exp Neurol. 2014;258:5-16

14. de Rivero Vaccari JP, Lotocki G, Marcillo AE, Dietrich WD, Keane RW. A molecular platform in neurons regulates inflammation after spinal cord injury. J Neurosci. 2008;28:3404-14.

15. Minkiewicz J, de Rivero Vaccari JP, Keane RW. Human astrocytes express a novel NLRP2 inflammasome. Glia. 2013;61:1113-21.

16. Zendedel A, Monnink F, Hassanzadeh G, Zaminy A, Ansar MM, Habib P, Slowik A, Kipp M, Beyer C. Estrogen attenuates local inflammasome expression and activation after spinal cord injury. Mol Neurobiol. 2018;55: 1364-75.

17. Zendedel A, Johann S, Mehrabi S, Joghataei MT, Hassanzadeh G, Kipp M, Beyer C. Activation and regulation of NLRP3 inflammasome by intrathecal application of SDF-1a in a spinal cord injury model. Mol Neurobiol. 2016;53: 3063-75.

18. Coll RC, Robertson A, Butler M, Cooper M, O'Neill LA. The cytokine release inhibitory drug CRID3 targets ASC oligomerisation in the NLRP3 and AIM2 inflammasomes. PLoS One. 2011;6:e29539.

19. Horiuchi H, Oshima Y, Ogata T, Morino T, Matsuda S, Miura H, Imamura T. Evaluation of injured axons using two-photon excited fluorescence microscopy after spinal cord contusion injury in YFP-H line mice. Int J Mol Sci. 2015;16:15785-99.

20. Wu J, Zhao Z, Kumar A, Lipinski MM, Loane DJ, Stoica BA, Faden Al. Endoplasmic reticulum stress and disrupted neurogenesis in the brain are associated with cognitive impairment and depressive-like behavior after spinal cord injury. J Neurotrauma. 2016;33:1919-35.

21. Ismael S, Nasoohi S, Ishrat T. MCC950, the selective inhibitor of nucleotide oligomerization domain-like receptor protein-3 inflammasome, protects mice against traumatic brain injury. J Neurotrauma. 2018;35:1294-303.

22. Coll RC, Robertson AA, Chae JJ, Higgins SC, Munoz-Planillo R, Inserra MC, Vetter I, Dungan LS, Monks BG, Stutz A, et al. A small-molecule inhibitor of the NLRP3 inflammasome for the treatment of inflammatory diseases. Nat Med. 2015;21:248-55.

23. Ismael S, Zhao L, Nasoohi S, Ishrat T. Inhibition of the NLRP3-inflammasome as a potential approach for neuroprotection after stroke. Sci Rep. 2018;8:5971.

24. Lin YH, Wu Y, Wang Y, Yao ZF, Tang J, Wang R, Shen L, Ding SQ, Hu JG, Lu $H Z$. Spatio-temporal expression of Hexokinase-3 in the injured female rat spinal cords. Neurochem Int. 2018:113:23-33.

25. Wu Y, Shen L, Wang R, Tang J, Ding SQ, Wang SN, Guo XY, Hu JG, Lu HZ. Increased ceruloplasmin expression caused by infiltrated leukocytes, activated microglia, and astrocytes in injured female rat spinal cords. J Neurosci Res. 2018:96:1265-76.

26. Lu HZ, Xu L, Zou J, Wang YX, Ma ZW, Xu XM, Lu PH. Effects of autoimmunity on recovery of function in adult rats following spinal cord injury. Brain Behav Immun. 2008;22:1217-30.

27. Teng YD, Mocchetti I, Wrathall JR. Basic and acidic fibroblast growth factors protect spinal motor neurones in vivo after experimental spinal cord injury. Eur J Neurosci. 1998;10:798-802.

28. Karimi-Abdolrezaee S, Eftekharpour E, Wang J, Morshead CM, Fehlings MG Delayed transplantation of adult neural precursor cells promotes remyelination and functional neurological recovery after spinal cord injury. J Neurosci. 2006;26:3377-89.

29. Basso DM, Fisher LC, Anderson AJ, Jakeman LB, McTigue DM, Popovich PG. Basso mouse scale for locomotion detects differences in recovery after 
spinal cord injury in five common mouse strains. J Neurotrauma. 2006;23: 635-59.

30. Hermiston $\mathrm{ML}, \mathrm{Xu} Z$ Z, Weiss $\mathrm{A}$. CD45: a critical regulator of signaling thresholds in immune cells. Annu Rev Immunol. 2003;21:107-37.

31. Thomas ML. The leukocyte common antigen family. Annu Rev Immunol. 1989;7:339-69.

32. Martin E, El-Behi M, Fontaine B, Delarasse C. Analysis of microglia and monocyte-derived macrophages from the central nervous system by flow cytometry. J Vis Exp. 2017.

33. Chen YJ, Zhu H, Zhang N, Shen L, Wang R, Zhou JS, Hu JG, Lu HZ. Temporal kinetics of macrophage polarization in the injured rat spinal cord. J Neurosci Res. 2015;93:1526-33.

34. Greaves DR, Gordon S. Macrophage-specific gene expression: current paradigms and future challenges. Int J Hematol. 2002;76:6-15.

35. Fu KY, Tan YH, Sung B, Mao J. Peripheral formalin injection induces unique spinal cord microglial phenotypic changes. Neurosci Lett. 2009;449:234-9.

36. Sedgwick JD, Ford AL, Foulcher E, Airriess R. Central nervous system microglial cell activation and proliferation follows direct interaction with tissue-infiltrating T cell blasts. J Immunol. 1998;160:5320-30

37. Feng $P$, Yan R, Dai X, Xie X, Wen H, Yang S. The alteration and clinical significance of Th1/Th2/Th17/Treg cells in patients with multiple myeloma. Inflammation. 2015;38:705-9.

38. Zhang Y, Zhang Y, Gu W, Sun B. TH1/TH2 cell differentiation and molecular signals. Adv Exp Med Biol. 2014;841:15-44.

39. Hu X, Liu X, Moisan J, Wang Y, Lesch CA, Spooner C, Morgan RW, Zawidzka EM, Mertz D, Bousley D, et al. Synthetic RORgamma agonists regulate multiple pathways to enhance antitumor immunity. Oncoimmunology. 2016;5:e1254854.

40. Grados A, Ebbo M, Piperoglou C, Groh M, Regent A, Samson M, Terrier B, Loundou A, Morel N, Audia S, et al. T cell polarization toward TH2/TFH2 and TH17/TFH17 in patients with IgG4-related disease. Front Immunol. 2017;8: 235.

41. Carvajal Gonczi CM, Tabatabaei Shafiei M, East A, Martire E, MauriceVentouris MHI, Darlington PJ. Reciprocal modulation of helper Th1 and Th17 cells by the beta2-adrenergic receptor agonist drug terbutaline. FEBS J. 2017:284:3018-28

42. Gosselin A, Monteiro P, Chomont N, Diaz-Griffero F, Said EA, Fonseca S, Wacleche V, El-Far M, Boulassel MR, Routy JP, et al. Peripheral blood CCR4+ CCR6+ and CXCR3+CCR6+CD4+ T cells are highly permissive to HIV-1 infection. J Immunol. 2010;184:1604-16.

43. Wu Q, Wang Q, Mao G, Dowling CA, Lundy SK, Mao-Draayer Y. Dimethyl fumarate selectively reduces memory $T$ cells and shifts the balance between Th1/Th17 and Th2 in multiple sclerosis patients. J Immunol. 2017; 198:3069-80.

44. Ge M, Zheng Y, Li X, Lu S, Li H, Chen F, Chen D, Shao Y, Shi J, Feng S. Differential expression profile of Th1/Th17/Th2-related chemokines and their receptors in patients with acquired bone marrow failure syndromes. Hum Immunol. 2013;74:176-80.

45. Lamkanfi M, Dixit VM. Inflammasomes and their roles in health and disease. Annu Rev Cell Dev Biol. 2012;28:137-61.

46. Strowig T, Henao-Mejia J, Elinav E, Flavell R. Inflammasomes in health and disease. Nature. 2012;481:278-86.

47. Jimenez Fernandez D, Lamkanfi M. Inflammatory caspases: key regulators of inflammation and cell death. Biol Chem. 2015;396:193-203.

48. Conforti-Andreoni C, Ricciardi-Castagnoli P, Mortellaro A. The inflammasomes in health and disease: from genetics to molecular mechanisms of autoinflammation and beyond. Cell Mol Immunol. 2011;8: $135-45$

49. Karasawa T, Takahashi M. Role of NLRP3 inflammasomes in atherosclerosis. J Atheroscler Thromb. 2017;24:443-51.

50. Sepehri Z, Kiani Z, Afshari M, Kohan F, Dalvand A, Ghavami S. Inflammasomes and type 2 diabetes: an updated systematic review. Immunol Lett. 2017;192:97-103.

51. White CS, Lawrence CB, Brough D, Rivers-Auty J. Inflammasomes as therapeutic targets for Alzheimer's disease. Brain Pathol. 2017;27:223-34.

52. Shin Jl, Lee KH, Joo YH, Lee JM, Jeon J, Jung HJ, Shin M, Cho S, Kim TH, Park $\mathrm{S}$, et al. Inflammasomes and autoimmune and rheumatic diseases: a comprehensive review. J Autoimmun. 2019;103:102299.

53. Mortezaee K, Khanlarkhani N, Beyer C, Zendedel A. Inflammasome: its role in traumatic brain and spinal cord injury. J Cell Physiol. 2018;233:5160-9.
54. de Rivero Vaccari JP, Dietrich WD, Keane RW. Activation and regulation of cellular inflammasomes: gaps in our knowledge for central nervous system injury. J Cereb Blood Flow Metab. 2014;34:369-75.

55. Awad F, Assrawi E, Louvrier C, Jumeau C, Georgin-Lavialle S, Grateau G, Amselem S, Giurgea I, Karabina SA. Inflammasome biology, molecular pathology and therapeutic implications. Pharmacol Ther. 2018;187:133-49.

56. Jiao J, Zhao G, Wang Y, Ren P, Wu M. MCC950, a selective inhibitor of NLRP3 inflammasome, reduces the inflammatory response and improves neurological outcomes in mice model of spinal cord injury. Front Mol Biosci. 2020;7:37.

57. Primiano MJ, Lefker BA, Bowman MR, Bree AG, Hubeau C, Bonin PD, Mangan M, Dower K, Monks BG, Cushing L, et al. Efficacy and pharmacology of the NLRP3 inflammasome inhibitor CP-456,773 (CRID3) in murine models of dermal and pulmonary inflammation. J Immunol. 2016;197:2421-33.

58. Popovich PG. Neuroimmunology of traumatic spinal cord injury: a brief history and overview. Exp Neurol. 2014;258:1-4.

59. Hu JG, Shen L, Wang R, Wang QY, Zhang C, Xi J, Ma SF, Zhou JS, Lu HZ Effects of Olig2-overexpressing neural stem cells and myelin basic proteinactivated $T$ cells on recovery from spinal cord injury. Neurotherapeutics. 2012;9:422-45.

60. Hu JG, Shi LL, Chen YJ, Xie XM, Zhang N, Zhu AY, Jiang ZS, Feng YF, Zhang C, Xi J, Lu HZ. Differential effects of myelin basic protein-activated Th1 and Th2 cells on the local immune microenvironment of injured spinal cord. Exp Neurol. 2016;277:190-201.

61. Ma SF, Chen YJ, Zhang JX, Shen L, Wang R, Zhou JS, Hu JG, Lu HZ. Adoptive transfer of $\mathrm{M} 2$ macrophages promotes locomotor recovery in adult rats after spinal cord injury. Brain Behav Immun. 2015;45:157-70.

62. Zhou X, He X, Ren Y. Function of microglia and macrophages in secondary damage after spinal cord injury. Neural Regen Res. 2014;9:1787-95.

63. Su XQ, Wang XY, Gong FT, Feng M, Bai JJ, Zhang RR, Dang XQ. Oral treatment with glycyrrhizin inhibits NLRP3 inflammasome activation and promotes microglial M2 polarization after traumatic spinal cord injury. Brain Res Bull. 2020;158:1-8.

64. Slusarczyk J, Trojan E, Glombik K, Piotrowska A, Budziszewska B, Kubera M, Popiolek-Barczyk K, Lason W, Mika J, Basta-Kaim A. Targeting the NLRP3 inflammasome-related pathways via tianeptine treatment-suppressed microglia polarization to the M1 phenotype in lipopolysaccharidestimulated cultures. Int J Mol Sci. 2018;19.

65. Aryanpour R, Pasbakhsh P, Zibara K, Namjoo Z, Beigi Boroujeni F, Shahbeigi S, Kashani IR, Beyer C, Zendehdel A. Progesterone therapy induces an M1 to M2 switch in microglia phenotype and suppresses NLRP3 inflammasome in a cuprizone-induced demyelination mouse model. Int Immunopharmacol. 2017:51:131-9.

66. Chen X, Ye J, Ye J. Analysis of peripheral blood lymphocyte subsets and prognosis in patients with septic shock. Microbiol Immunol. 2011;55:736-42.

67. Wang CY, Ding HZ, Tang X, Li ZG. Effect of Liuweibuqi capsules on CD4(+ )CD25(+)Foxp3(+) regulatory T cells, helper T cells and lung function in patients with stable chronic obstructive pulmonary disease complicated with lung Qi deficiency. J Thorac Dis. 2018;10:2700-11.

68. Yang X, Gao T, Shi R, Zhou X, Qu J, Xu J, Shan Z, Teng W. Effect of iodine excess on Th1, Th2, Th17, and Treg cell subpopulations in the thyroid of NOD.H-2 h4 mice. Biol Trace Elem Res. 2014;159:288-96.

69. Nikitina IY, Panteleev AV, Kosmiadi GA, Serdyuk YV, Nenasheva TA, Nikolaev AA, Gorelova LA, Radaeva TV, Kiseleva YY, Bozhenko VK, Lyadova IV. Th1, Th17, and Th1Th17 lymphocytes during tuberculosis: Th1 lymphocytes predominate and appear as low-differentiated CXCR3(+)CCR6(+) cells in the blood and highly differentiated CXCR3(+/-)CCR6(-) cells in the lungs. J Immunol. 2018;200:2090-103.

70. de Castro LF, Longhi LNA, Paiao MR, Justo-Junior ADS, de Jesus MB, Blotta $M$, Mamoni RL. NLRP3 inflammasome is involved in the recognition of Paracoccidioides brasiliensis by human dendritic cells and in the induction of Th17 cells. J Infect. 2018;77:137-44.

71. Zhu C, Zhang L, Liu Z, Li C, Bai Y, Wang L. Atractylenolide III reduces NLRP3 inflammasome activation and Th1/Th2 imbalances in both in vitro and in vivo models of asthma. Clin Exp Pharmacol Physiol. 2020.

72. Deng J, Yu XQ, Wang PH. Inflammasome activation and Th17 responses. Mol Immunol. 2019;107:142-64.

\section{Publisher's Note}

Springer Nature remains neutral with regard to jurisdictional claims in published maps and institutional affiliations. 